\title{
Seasonal cycle in the upper equatorial Atlantic Ocean
}

\author{
Hui Ding, ${ }^{1}$ Noel S. Keenlyside, ${ }^{1}$ and Mojib Latif ${ }^{1}$ \\ Received 2 April 2009; revised 5 June 2009; accepted 29 June 2009; published 18 September 2009.
}

[1] The dynamics of the seasonal cycle in the upper equatorial Atlantic ocean are studied using observations and a hierarchy of ocean models. Distinctive features of the seasonal cycle are strong annual and semiannual components: eastward (westward) propagating sea surface height (SSH) and thermocline depth at the equator (off the equator) and westward propagating surface zonal currents at the equator. Modelling results show that linear theory can explain the seasonal cycle in thermocline depth and SSH. While firstorder linear theory can also explain the structure of the seasonal cycle of surface zonal currents at the equator, nonlinear terms are required; they weaken the variability and improve its phase and zonal extent. The important terms are meridional and vertical advection and vertical diffusion of zonal momentum. The linear solution is essentially determined by the four gravest baroclinic modes and Kelvin and first meridional mode Rossby waves. The eastward propagation in thermocline depth at the equator results from the Kelvin wave contribution, while the westward propagation in thermocline depth off the equator and surface zonal currents at the equator result from the first meridional mode Rossby wave. The contribution of Kelvin and Rossby waves generated by boundary reflections equals that of the directly forced waves. The semiannual cycle in zonal winds although much weaker than the annual component forces a strong semiannual component in SSH and surface zonal currents, because it excites the basin mode of the second baroclinc mode. This explains the observed feature in the seasonal cycle from March to August.

Citation: Ding, H., N. S. Keenlyside, and M. Latif (2009), Seasonal cycle in the upper equatorial Atlantic Ocean, J. Geophys. Res., 114, C09016, doi:10.1029/2009JC005418.

\section{Introduction}

[2] In the equatorial Atlantic, sea surface temperature (SST) variability is dominated by the seasonal cycle, while interannual fluctuations are comparatively weak [Xie and Carton, 2004]. This picture contrasts that in the Pacific, where interannual variability and the annual cycle are of similar strength. While interannual variability in both basins is tightly phase locked to the seasonal cycle, it is to different seasons: In the Atlantic (Pacific) variability is strongest in boreal summer (winter). The seasonal cycle of SST in both basins, although exhibiting similarities in phase and strength (Figures 1c and 1d), display distinct relationships to zonal wind stress (Figures 1a and 1b). In the Pacific, SST and zonal wind stress variations are consistent with a mixed layer mode [e.g., Chang and Philander, 1994; Xie, 1994], but they are not in the Atlantic. These differences may at first seem quite surprising, given that the equatorial annual cycle and interannual variability interact with each other [e.g., Tziperman et al., 1994; Chang et al., 1995; Liu, 2002; Keenlyside and Latif, 2007], and if as previously assumed the mechanisms for the seasonal cycle in both basins are the same [e.g., Chang and Philander, 1994; Xie, 1994]. The seasonal cycle

${ }^{1}$ Leibniz Institute of Marine Sciences, Kiel University, Kiel, Germany.

Copyright 2009 by the American Geophysical Union. 0148-0227/09/2009JC005418\$09.00 of ocean dynamics are, however, very different (Figures 1e1h): In the Atlantic, thermocline depth [Houghton, 1983; Philander and Pacanowski, 1986; Xie and Carton, 2004] and surface zonal current [Foltz et al., 2003] variations are both strong, while in the Pacific thermocline variations are relatively weak [Yu and McPhaden, 1999]. Furthermore, in the Atlantic both quantities exhibit strong annual and semiannual components, whereas in the Pacific the annual harmonic dominates. The SST, thermocline depth and zonal current fluctuations also exhibit quite different relationships in the Atlantic and Pacific, as are the seasonal heat budget of the mixed layer [e.g., Wang and McPhaden, 1999; Foltz et $a l ., 2003]$. The aim of this paper is to better understand the dynamics of the seasonal cycle in the Atlantic.

[3] Great progress has been made in understanding seasonal variations in the Atlantic of thermocline depth and dynamic height through analyzing observations and a wide range of modeling studies, including linear vertical (single and multiple) mode, reduced gravity, and primitive equation models [e.g., Adamec and O'Brien, 1978; Busalacchi and Picaut, 1983; du Penhoat and Treguier, 1985; du Penhoat and Gouriou, 1987; Philander and Pacanowski, 1986; Weisberg and Tang, 1983, 1985, 1987, 1990]. However, certain aspects are still not well understood. One is that sea surface height propagates eastward at the equator and westward off the equator, as shown by Schouten et al. [2005]. They argued that equatorial waves produce these 
(o) Pocific toux (ON)

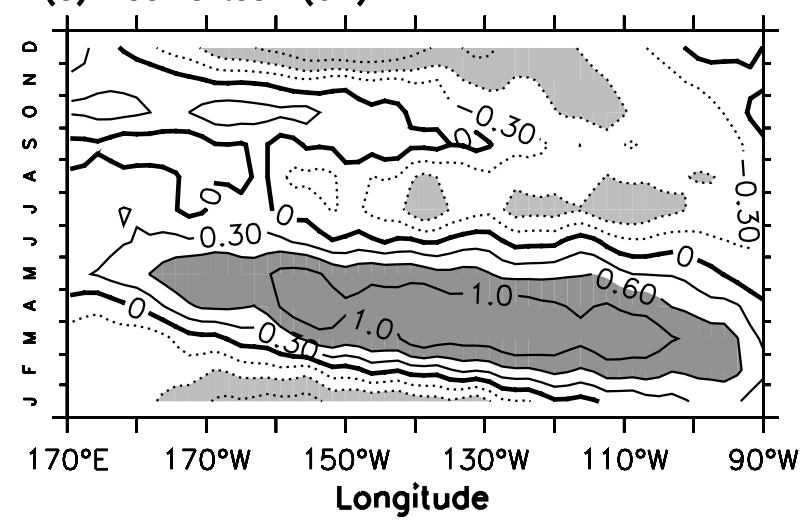

(c) Pocific SST (ON)

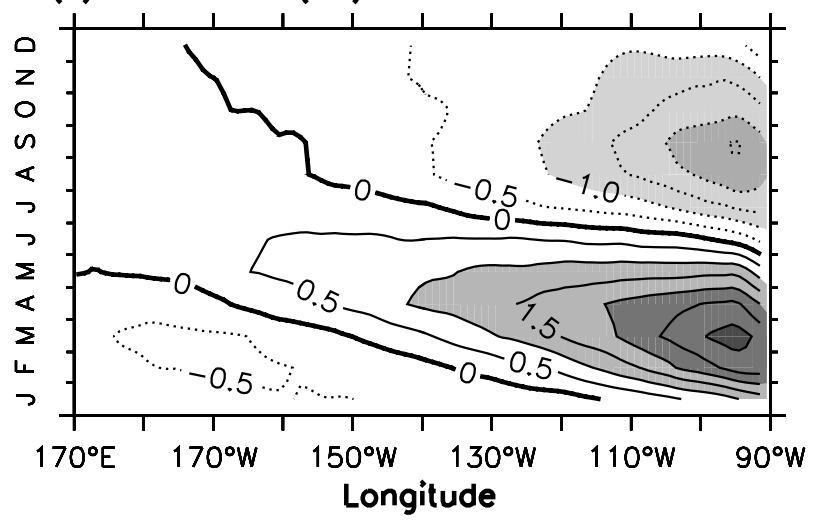

(e) Pocific Z20 (ON)

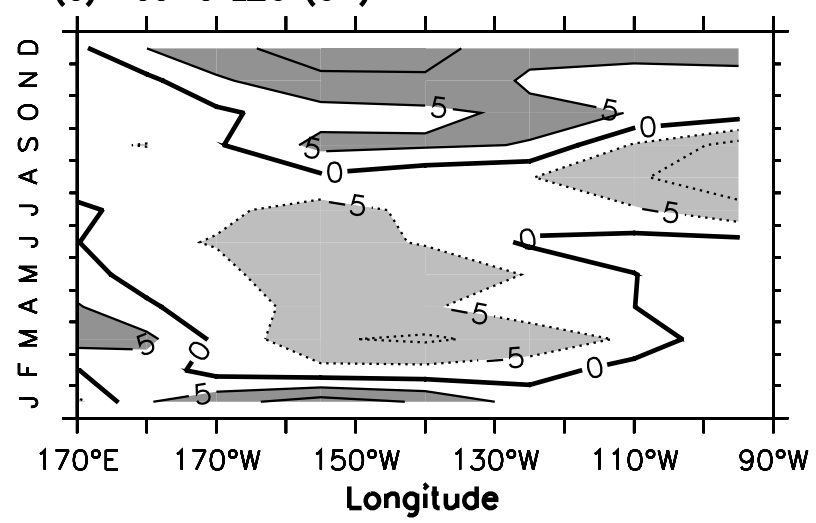

(g) Pocific U (ON)

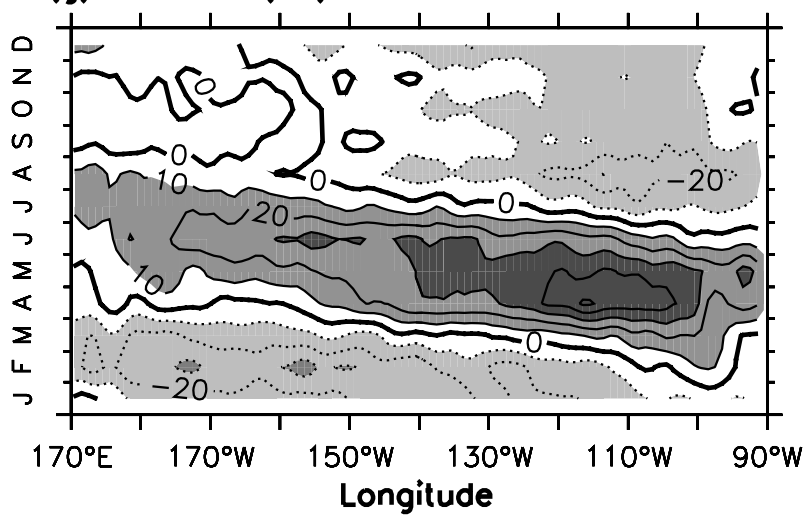

(b) Atlontic toux (ON)

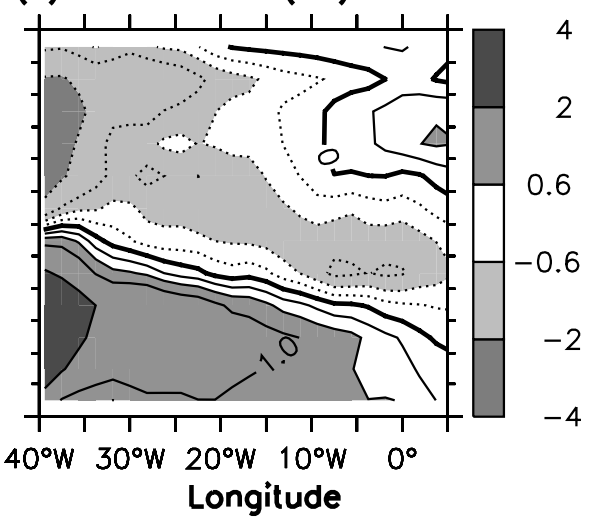

(d) Atlontic SST (ON)

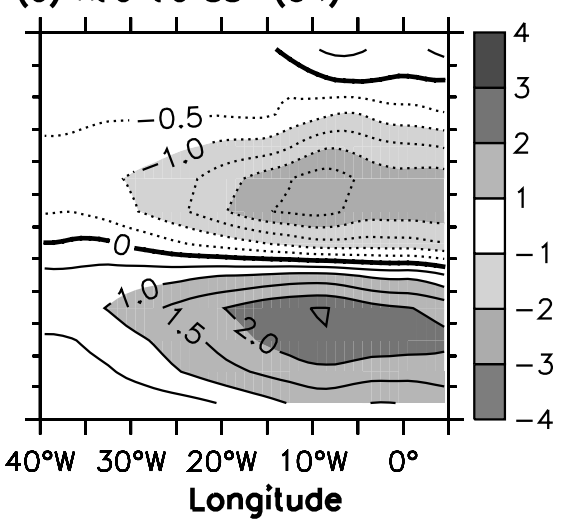

(f) Atlontic Z20 (ON)

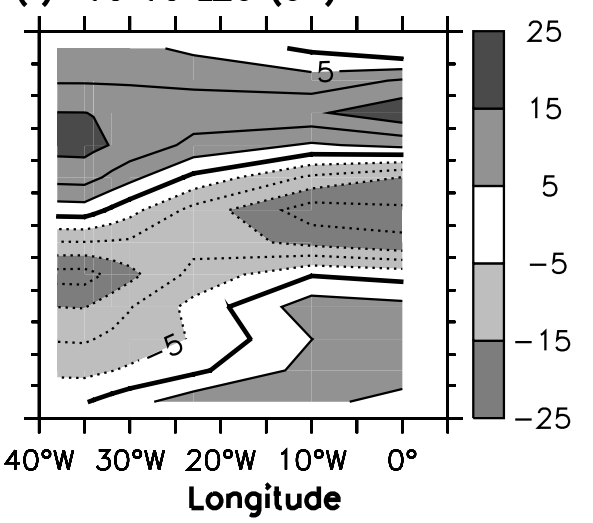

(h) Atlontic U (ON)

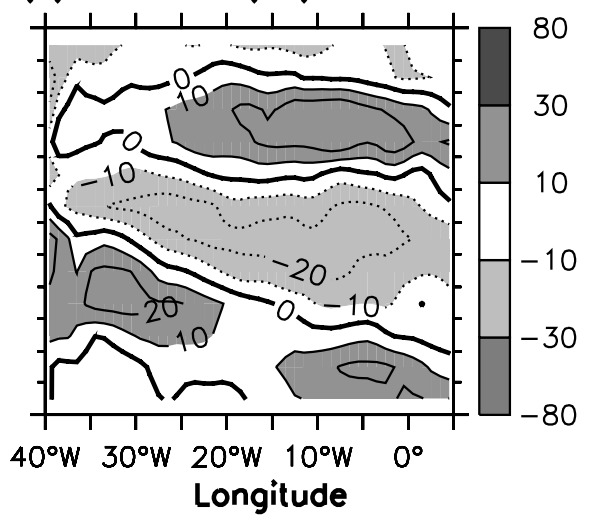

Figure 1 
propagation features. However, Bunge and Clarke [2009] found a discrepancy between theoretical Kelvin waves phase speeds and the eastward propagation of sea level along the equator during boreal summer. Therefore, they argue that the latter is best explained as the interaction between two independent (empirical orthogonal function) modes that describe a recharge discharge of equatorial heat content (analogous to the mechanism proposed by Jin [1997] for El Niño).

[4] A second aspect is the effects of nonlinear dynamics on equatorial surface zonal currents. According to observed data (mainly SEQUAL/FOCAL field and historical ship drift), surface zonal currents also display robust seasonal variations [Molinari, 1983; Richardson and McKee, 1984; Reverdin and McPhaden, 1986; Richardson and Walsh, 1986; Philander and Pacanowski, 1986; Richardson and Reverdin, 1987; Richardson et al., 1992; Arnault et al., 1999], especially the western North Equatorial Countercurrent (NECC) and equatorial branch of the South Equatorial Currents (SEC). du Penhoat and Treguier [1985] showed that linear dynamics can simulate the seasonal variability in NECC, but not in the equatorial branch of SEC. They speculated that the failure in simulating SEC is probably due to nonlinear dynamics, for instance vertical advection [Philander and Pacanowski, 1980].

[5] A third aspect is the prominent semiannual cycle in surface currents and sea surface height (SSH), occurring despite a comparatively weak semiannual cycle in surface winds (Figure 1b). Here it is argued that this feature results from the excitation of a basin mode (i.e., a free solution of equatorial ocean dynamics). Physically, the basin mode can be related to the circuit of a disturbance about the basin associated with the Kelvin and first meridional Rossby waves [Cane and Moore, 1981]. In the Atlantic, the period of the basin mode of the second baroclinic modes is 220 days and close to semiannual. A similar argument was previously used to explain the strong semiannual signal in the deep tropical Atlantic [Thierry et al., 2004].

[6] In this study, we investigate the dynamics of the mean seasonal cycle in the equatorial Atlantic, addressing the specific issues raised above. We mainly rely on analysis of observations and ocean model simulations forced with observed winds. The remainder of this paper is as follows. Section 2 describes the observations and models used in this study. Section 3 presents the observed mean seasonal cycle. In section 4 , a hierarchy of ocean model simulations are presented and used to explain the dynamics of the seasonal cycle, including its phase propagation features.

\section{Data and Model}

[7] In this study, the mean seasonal cycle is computed from a suite of satellite and in situ observations, and reanalysis. Except where otherwise mentioned, the period considered is 1993-2007, and only anomalies with respect to the annual mean are shown.

[8] Monthly mean NOAA optimum interpolation (OI) SST V2 are used here from the NOAA/OAR/ESRL PSD, Boulder, Colorado, USA (http://www.cdc.noaa.gov/). The SST analysis is produced weekly on a $1^{\circ}$ grid, using in situ and satellite SST. Before the analysis is computed, the satellite data is adjusted for biases using the method of Reynolds [1988] and Reynolds and Marsico [1993]. The NOAA OI.v2 SST monthly fields are derived by a linear interpolation of the weekly fields to daily fields then averaging the daily values over a month.

[9] Thermocline depth is defined as the depth of the $20^{\circ} \mathrm{C}$ isotherm. It is computed from temperature data from the Pilot Research Moored Array in the Tropical Atlantic (PIRATA) [Servain et al., 1998] at four locations along the equator: $35^{\circ} \mathrm{W}, 23^{\circ} \mathrm{W}, 10^{\circ} \mathrm{W}$, and $0^{\circ} \mathrm{W}$. At $0^{\circ} \mathrm{W}$ and $10^{\circ} \mathrm{W}$ data are not continuous, but in total there are about 7 and 5 years of data, respectively. At $23^{\circ} \mathrm{W}$ and $35^{\circ} \mathrm{W}$, data records are about 9 years long and continuous. As interannual variability is weak in comparison to the seasonal cycle, the data although short are sufficient to describe the seasonal cycle. To calculate the mean seasonal cycle, daily mean time series are averaged to monthly means. Off the equator, PIRATA data are insufficient to describe the seasonal cycle. Thus, Archiving, Validation, and Interpretation of Satellite Oceanographic data (AVISO) SSH products are employed. In the tropics, SSH and thermocline depth variations are closely related. These data are from the Topex/Poseidon and ERS satellites and are available since 1992.

[10] The Ocean Surface Current Analyses-Realtime (OSCAR) surface currents are derived from gridded $\mathrm{SSH}$, surface wind, and SST data, using a combination of the geostrophic, Ekman-Stommel, and thermal wind approximations, with a special treatment of the equatorial singularity [Bonjean and Lagerloef, 2002]. The data compare favorably with drifter data and in situ observations. In addition to the OSCAR data, a drifter-derived climatology of global near-surface currents are also used [Lumpkin and Garraffo, 2005].

[11] Three models are used in this study. The first is a global state of the art ocean general circulation model (OGCM), the Max-Planck-Institute for Meteorology Ocean Model (MPI-OM) [Marsland et al., 2003]. The model is forced with the National Centers for Environmental Prediction (NCEP)/National Center for Atmospheric Research (NCAR) reanalysis [Kalnay et al., 1996] for the period 1950-2001, using standard bulk formulas for the calculation of heat fluxes and a weak relaxation of surface salinity to the Levitus et al. [1994] climatology. Here only the period $1986-2000$ is considered.

Figure 1. Seasonal cycle of (a and b) zonal wind stress (taux), (c and d) sea surface temperature (SST), (e and f) $20^{\circ} \mathrm{C}$ isotherm depth (Z20), and ( $g$ and $\mathrm{h}$ ) surface zonal currents at the equator in the Pacific and Atlantic. Anomalies with respect to the annual mean are shown. Wind stress are from the NCEP/NCAR reanalysis [Kalnay et al., 1996]. SST are from NOAA [Reynolds et al., 2002], and surface zonal currents are from OSCAR [Bonjean and Lagerloef, 2002]. The 20 ${ }^{\circ} \mathrm{C}$ isotherm depth in the Pacific and Atlantic are from the Tropical Atmosphere-Ocean [McPhaden et al., 1998] and PIRATA [Servain et al., 1998] arrays, respectively. The contours for zonal wind stress are $-2,-1,-0.6,-0.3,0,0.3,0.6,1$, and $2 \times 10^{-2} \mathrm{~N} \mathrm{~m}^{-2}$. Contour interval of SST, Z20, and surface zonal currents are $0.5^{\circ} \mathrm{C}, 5 \mathrm{~m}$, and $10 \mathrm{~cm} \mathrm{~s}{ }^{-1}$, respectively. 
[12] The second model is an intermediate ocean model (IOM) designed to simulate the dynamical response of the equatorial ocean to wind forcing [Keenlyside, 2001; Keenlyside and Kleeman, 2002]. The model consists of linear and nonlinear components. The linear component is basically the model of McCreary [1981], but takes into account horizontally varying background stratification. It consists of ten baroclinic modes plus two surface layers. The two surface layers are governed by Ekman dynamics and represent baroclinic modes 11-30. The nonlinear component is a simplified treatment of the residual equations of motion (i.e., after removing linear terms) for zonal momentum and is solved in the two surface layers. These nonlinear terms are important in the surface zonal momentum budget in the equatorial Atlantic [Philander and Pacanowski, 1980], which cannot be fully described by linear dynamics [du Penhoat and Treguier, 1985]. Linear and nonlinear components are calculated independently so that their contributions can be investigated separately. Model equations and parameters are fully described by Keenlyside [2001].

[13] The model is configured for the Atlantic basin between $30^{\circ} \mathrm{S}-30^{\circ} \mathrm{N}$ and takes into account realistic coasts, where the no slip lateral boundary condition is applied. An Arakawa c grid is used with 2 degree zonal grid spacing, and a stretched meridional grid, with 0.5 degree grid spacing within 10 degrees of the equator, extending to 3 degrees at the boundaries. The vertical grid has 31 levels with 8 levels in the surface $125 \mathrm{~m}$ and a $4500 \mathrm{~m}$ flat bottom. The two surface Ekman layers cover the upper $125 \mathrm{~m}$ and are divided by the mixed layer depth. The model is integrated using a standard leapfrog scheme, with a time step of 5000 seconds, and filtering every 60 time steps. The model is forced only by surface wind stress from the NCEP reanalysis [Kalnay et al., 1996] for the period 1980-2007. The period 1993-2007 is considered here. The baroclinic modes and corresponding shallow water speeds are calculated from the Levitus climatological temperature [Locarnini et al., 2006] and salinity [Antonov et al., 2006] data.

[14] The third model is a simple meridional mode model of the first four baroclinic modes, and is essentially the model of Gill and Clarke [1974]. It is used to decompose the linear solution of the IOM into Kelvin and Rossby waves and to investigate the contribution of boundary reflections. Model parameters are chosen to match those of the IOM. The long wave approximation is taken, filtering out high-frequency inertia gravity and short Rossby waves. In addition, meridional wind stress is neglected, as it is relatively inefficient at exciting a dynamical response in the equatorial ocean on seasonal time scales [Gent et al., 1983; Yu and McPhaden, 1999]. The eastern and western boundary conditions are $u=0$ and $\int_{v_{s}}^{y_{n}} u d y=0$, respectively. The latter accounts for the fact that short Rossby waves are filtered from the solution [Cane and Sarachik, 1981]. The model domain extends from $45^{\circ} \mathrm{W}$ to $5^{\circ} \mathrm{E}$ in longitude, but is unbounded meridionally. The influence from the Gulf of Guinea and Brazilian coast on the propagation of planetary waves at the equator is assumed negligible. This assumption is not made in the other two models, but appears reasonable as this model can reproduce the key features simulated by those models. Weisberg and Tang [1983, 1985, 1987, 1990] also made the same assumption and were successful in reproducing many features of seasonal variations of the thermocline at the equator. The zonal wind stress used to drive the model is the climatologically monthly mean of the NCEP reanalysis [Kalnay et al., 1996] from 1993 to 2007. The model is run for 3 years and only the third year is analyzed, when the simulated seasonal variations have stabilized. Calculations are limited to the Kelvin and first meridional mode Rossby waves.

\section{Observed Seasonal Cycle}

[15] In the western Atlantic the seasonal cycle in zonal wind stress (Figure 1b) is dominated by an annual cycle, while in the east a semiannual cycle is apparent. In April, westward stress firstly appears in the eastern part and then moves westward [Picaut, 1983]. In contrast to zonal winds, the meridional wind stress (not shown) does not exhibit a semiannual component.

[16] The annual mean equatorial thermocline slopes upward toward the east, and is around $100 \mathrm{~m}$ in the west and $50 \mathrm{~m}$ in the east (not shown). An interesting aspect is that seasonal variations have larger amplitude on the eastern and western sides of the basin, rather than at the center and are about $90^{\circ}$ out of phase from March to July (Figure 1f), which is reminiscent of the basin mode [Cane and Moore, 1981]. In the west the annual cycle is dominant, with minimum (maximum) depth occurring in May (September). These variations are mainly a direct response to zonal wind stress (Figure 1b) [Philander and Pacanowski, 1986]. In April and May, the thermocline is most close to surface in the western Atlantic, responding to the relaxation in zonal winds (Figure 1b). The shallow thermocline in April-May progresses eastward and reaches the Gulf of Guinea in boreal summer, when the thermocline depth there decreases by almost half (not shown). These changes are closely related to the rapid decrease in SST there (Figure 1d). The deepening of the thermocline in the west in September also propagates eastward, but the propagation is much more rapid than for the shoaling (Figure 1f). Toward the east a semiannual cycle also appears in the thermocline variability, and in the far east it is almost as strong as the annual cycle. In the tropics sea level and thermocline variations are closely related, and the observed sea-surface variations at the equator (Figure 2a) corroborate the picture from PIRATA.

[17] Off the equator, SSH also exhibit a pronounced seasonal cycle (Figures $2 \mathrm{~b}$ and $2 \mathrm{c}$ ), with significant annual and semiannual cycles in the west and east, respectively, similar to that at the equator. The seasonal cycle contributes to over a half of the total variability in SSH [Schouten et al., 2005]. In contrast to that at the equator, SSH variations off the equator propagate westward. As mentioned above, PIRATA data are insufficient off the equator to describe seasonal variations in thermocline depth. WOA05 climatological monthly ocean temperature data [Locarnini et al., 2006] show variations consistent with the satellite SSH data off (and at) the equator (not shown).

[18] The seasonal cycle of surface zonal currents along the equator in the Atlantic is dominated by a semiannual cycle and is strongest in the central part of the basin (Figure 1h) [Richardson and McKee, 1984]. Seasonal variations propagate westward along the equator during the first half of calendar year. At the beginning of the year, the zonal 

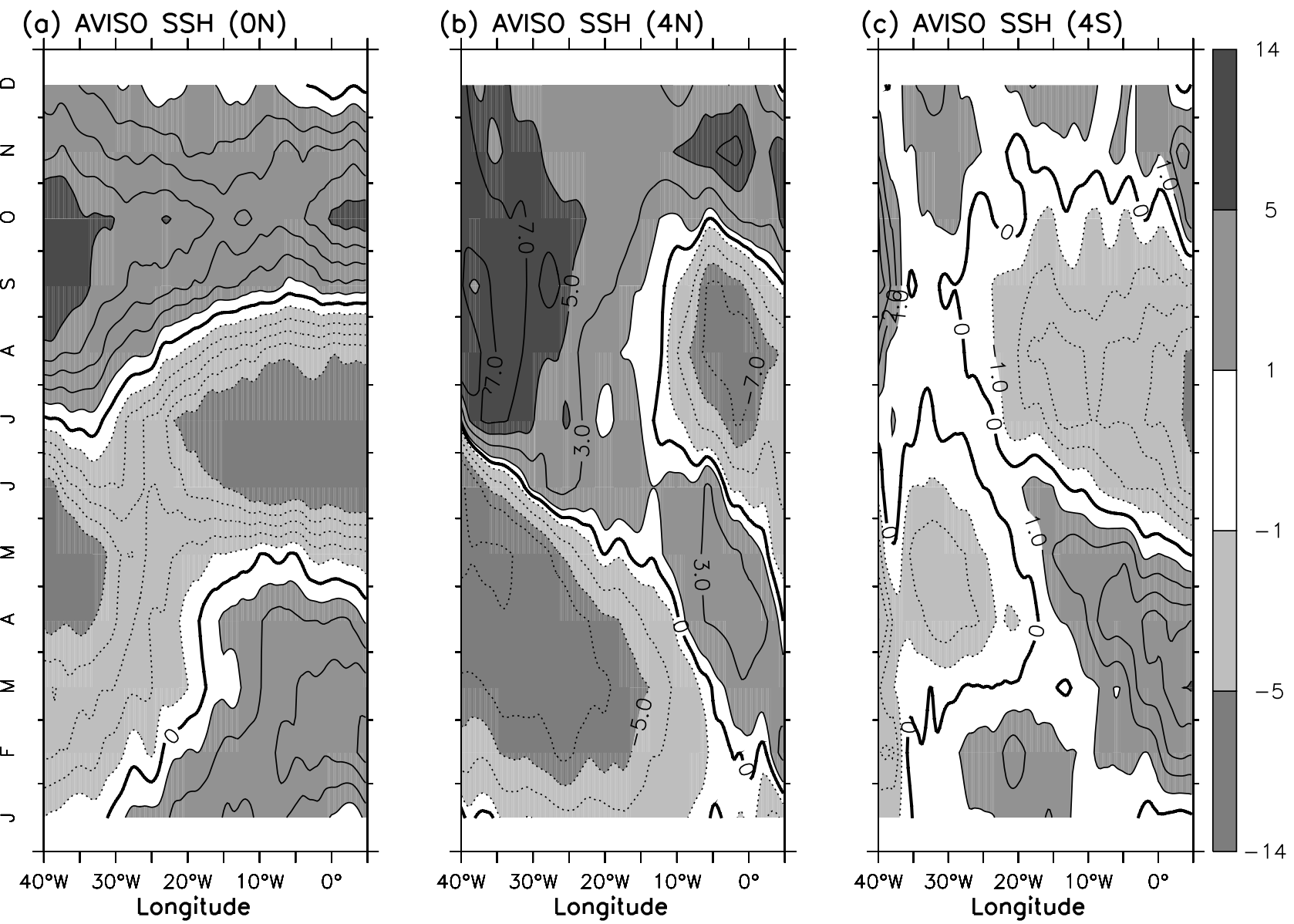

Figure 2. Seasonal cycle of sea surface height (SSH) at (a) the equator, (b) $4^{\circ} \mathrm{N}$, and (d) $4^{\circ} \mathrm{S}$. Anomalies with respect to the annual mean are shown. SSH are from AVISO (http://www.aviso.oceanobs.com/). Contour interval of SSH at the equator and $4^{\circ} \mathrm{S}$ is $1 \mathrm{~cm}$. Contours of $-12,-7,-5,-3,-1,0,1,3,5,7$, and $12 \mathrm{~cm}$ are shown for $\mathrm{SSH}$ at the $4^{\circ} \mathrm{N}$.

current anomaly is eastward (weak and westward) in the east (west). The eastward anomaly then propagates westward, reaching $35^{\circ} \mathrm{W}$ in April and May. In the east when zonal wind stress strengthens in April (Figure 1b), the eastward zonal currents anomaly reverses sign and propagates westward along the equator. Enhanced zonal currents persist until about August. Before August, seasonal variations of zonal currents and zonal wind stress along the equator have similar phase, direction, and propagation characteristics [Richardson and McKee, 1984]. After August, zonal current anomaly is eastward in September and October. The eastward anomaly extends almost simultaneously across the whole equatorial Atlantic, although the amplitude varies with longitude, being stronger between about $20^{\circ} \mathrm{W}$ and $0^{\circ} \mathrm{W}$. The seasonal cycle of zonal currents at the equator from drifters (not shown), although very noisy and with stronger amplitude, corroborates the features seen in the OSCAR data.

[19] The $90^{\circ}$ out of phase relationship between east-west gradient of sea level and surface zonal currents from March to August (Figure 3a) shows signs of the basin mode. At the peak of the positive phase (Figure 3b), the zonal currents are weak and the zonal east-west gradient is at its maximum. The gradient drives westward currents that in turn weaken the gradient. The currents are strongest during the transition phase (Figure 3c), when the gradient is almost zero. The signal of the basin mode is clear from March until about August and then becomes less clear (Figure 3a).

\section{Dynamics of the Seasonal Cycle}

[20] The dynamics of seasonal cycle are now investigated using the three models. Both the OGCM and IOM reproduce the seasonal cycle in SSH on and off the equator well (Figure 4). In particular, at the equator the annual cycle in the west and semiannual cycle in the east are simulated by both models (Figures 4a and 4d), including the rapid sealevel decrease in the cold tongue during boreal summer, and the basin-wide increase in sea level in September and October. A deficiency of both models is that simulated SSH variations are too weak, and in the west they lead observations by about one month and are in phase with the zonal wind variations; a problem previously noted [Philander and Pacanowski, 1986]. The reasons for this deficiency are not clear, but may result from errors in the forcing data or in model physics. As this region is directly under the ITCZ, the contribution of precipitation to sea level may be also important. Along $4^{\circ} \mathrm{N}$, despite being generally too weak, both models (Figures $4 \mathrm{~b}$ and $4 \mathrm{e}$ ) reproduce the basic pattern of the seasonal cycle (Figure 2b), prominent annual 
(a) dSSH and zc

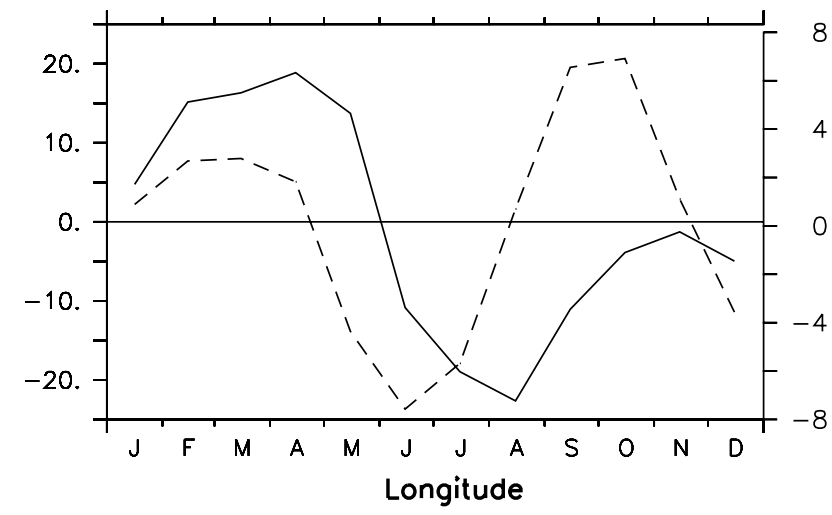

(c) Transient phose

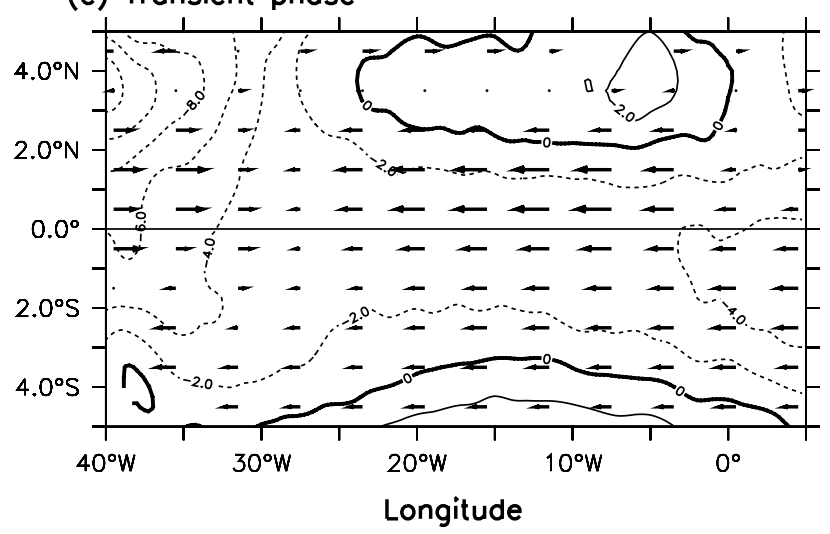

(b) Positive phase

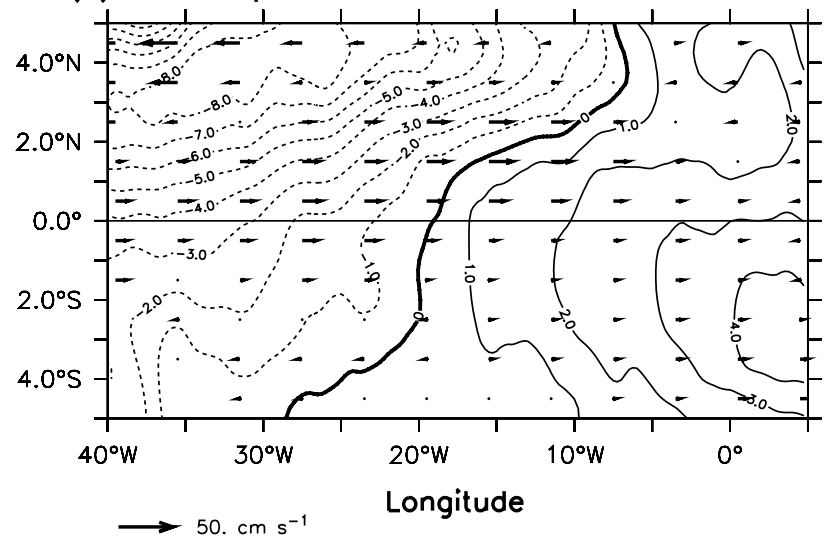

(d) Negative phase

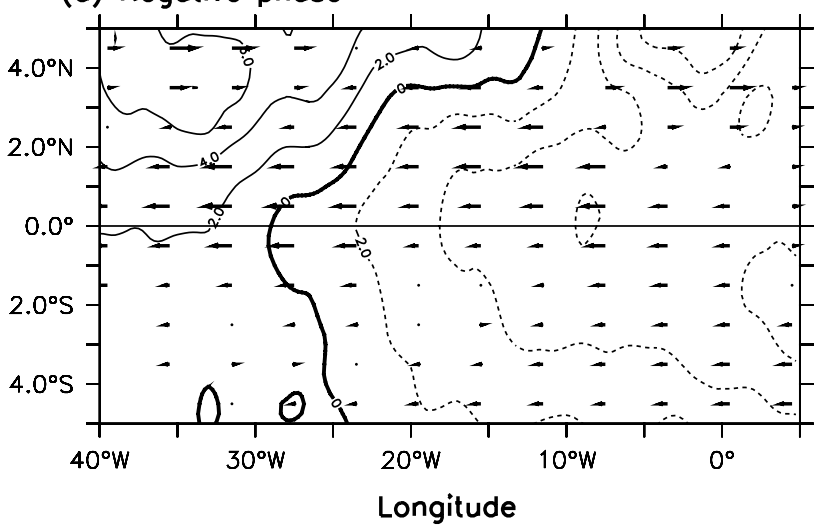

Figure 3. (a) The seasonal variations of east-west gradient of SSH (solid line) and surface zonal currents (dashed line). Here, east-west gradient denotes the difference between SSH averaged from $15^{\circ} \mathrm{W}$ to $5^{\circ} \mathrm{E}$ and $\mathrm{SSH}$ averaged from $45^{\circ} \mathrm{W}$ to $25^{\circ} \mathrm{W}$ at the equator and surface zonal currents are averaged from $25^{\circ} \mathrm{W}$ to $10^{\circ} \mathrm{W}$ at the equator. (b-d) SSH (contours) and surface zonal currents (vectors) for positive (March and April), transient (May and June), and negative (July and August) phases, respectively. The contour interval is $1 \mathrm{~cm}$.

and semiannual cycles in the west and east, respectively. The westward propagation is also well reproduced. Along $4^{\circ} \mathrm{S}$, both simulations (Figures $4 \mathrm{c}$ and $4 \mathrm{f}$ ) also compare well to observations (Figure 2c). The westward propagation of the positive anomaly at the beginning of the year is as observed, but it is stronger and slightly phase shifted, especially in the west.

[21] The seasonal cycle of the surface zonal currents at the equator is also simulated well by both models (Figures 5a and $5 \mathrm{~b}$ ), in terms of amplitude and structure. In particular, the models correctly simulate a semiannual cycle along the whole equatorial Atlantic, including the boreal summer westward currents anomalies and their westward propagation. Differences exist among the observations and the two model simulations, but they are of similar order to the differences between OSCAR (Figure 1h) and drifter (not shown) data. Another difference is that MPI-OM surface zonal currents display a westward propagation from September to December, but observed currents are almost stationary; however, this may be partly due to different periods considered (section 2). Separating the IOM surface zonal currents into linear (Figure 5c) and nonlinear (Figure 5d) components, shows that the linear solution has a lot of resemblance to observations. In particular, the observed westward propagation and semiannual cycle are captured, except in September and October when the linear solution is unable to reproduce the observed basin wide eastward currents anomalies. Another deficiency is that the strength of the currents in the linear component are too large (about three times the observed strength) consistent with previous work [du Penhoat and Treguier, 1985]. Comparing total, linear and nonlinear surface zonal currents (Figures $5 b-5 d$ ), shows that the nonlinear terms have equal magnitude to linear terms and play an important role. They weaken the linear terms and lead to realistic zonal currents strength and they also cause the eastward currents anomaly to extend along the entire equator in September and October. Thus, the nonlinear terms provide a necessary correction to the linear solution, contributing significantly to the strength and phase of simulated currents.

[22] The terms in the nonlinear equations are zonal, meridional and vertical advection of zonal velocity and horizontal and vertical diffusion of nonlinear zonal velocity. The most significant terms are meridional advection, vertical diffusion, and vertical advection; zonal advection is negligible (Figure 6). The driving terms are meridional 
(a) MPI-OM SSH (ON)

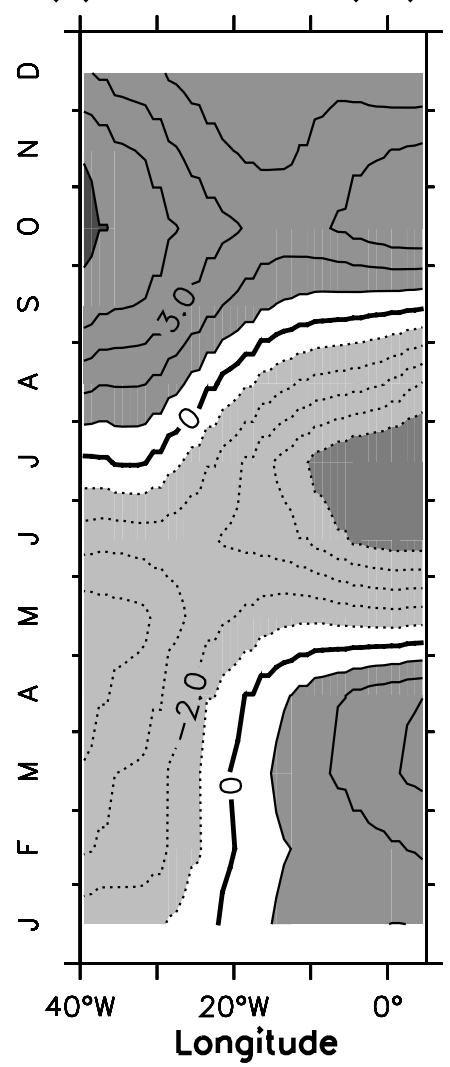

(d) IOM SSH (ON)

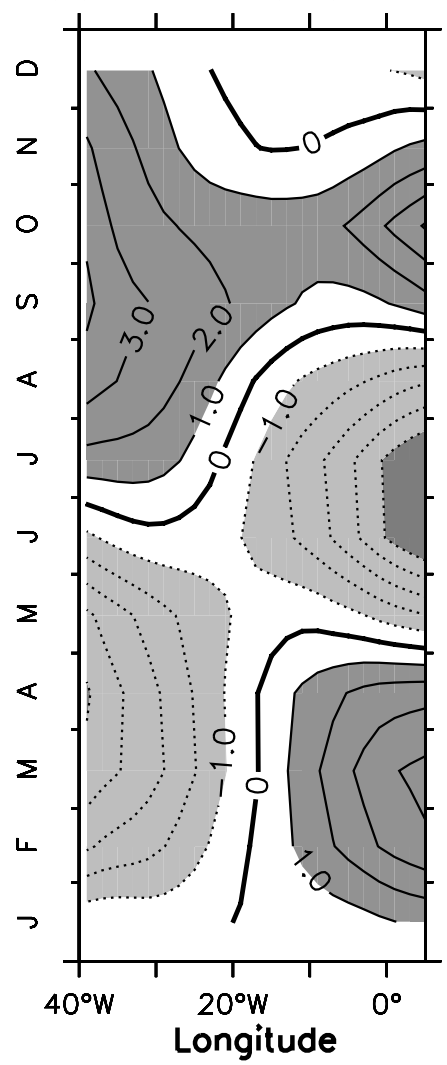

(b) MPI-OM SSH (4N)

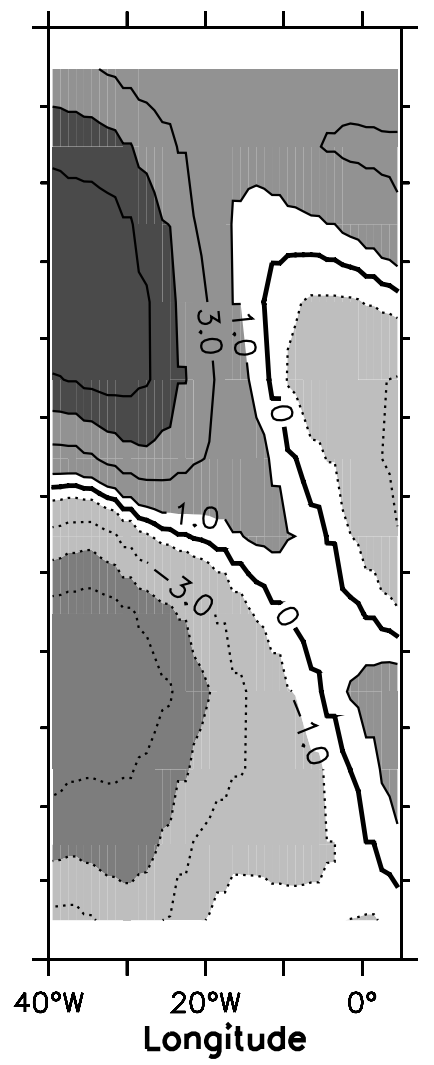

(e) IOM SSH (4N)

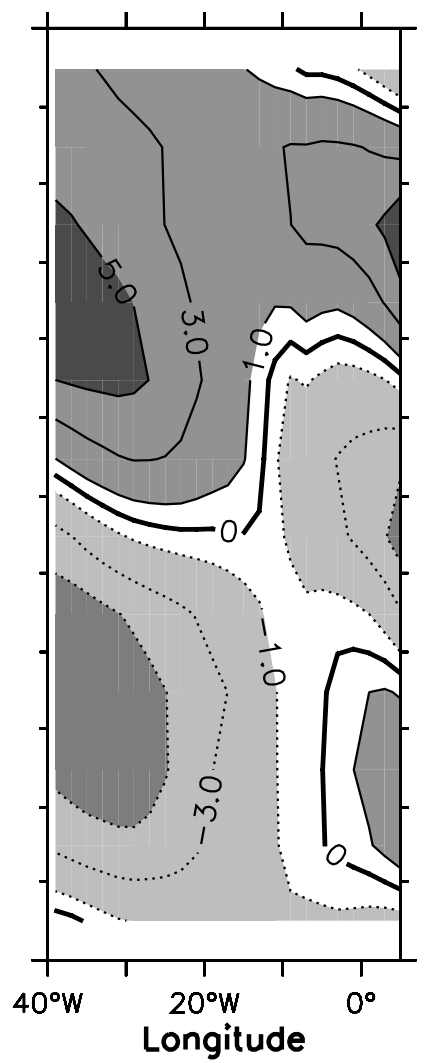

(c) MPI-OM SSH (4S)

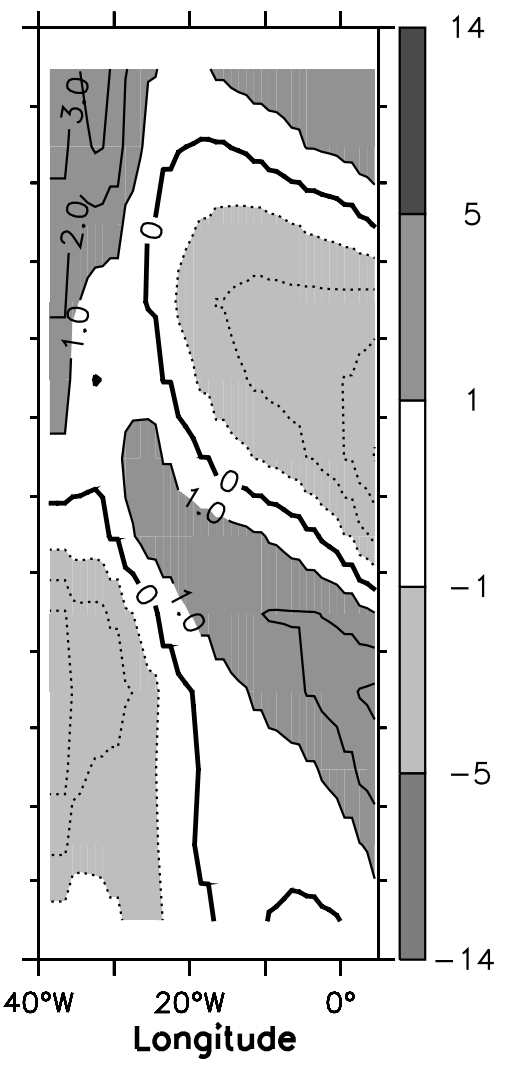

(f) IOM SSH (4S)

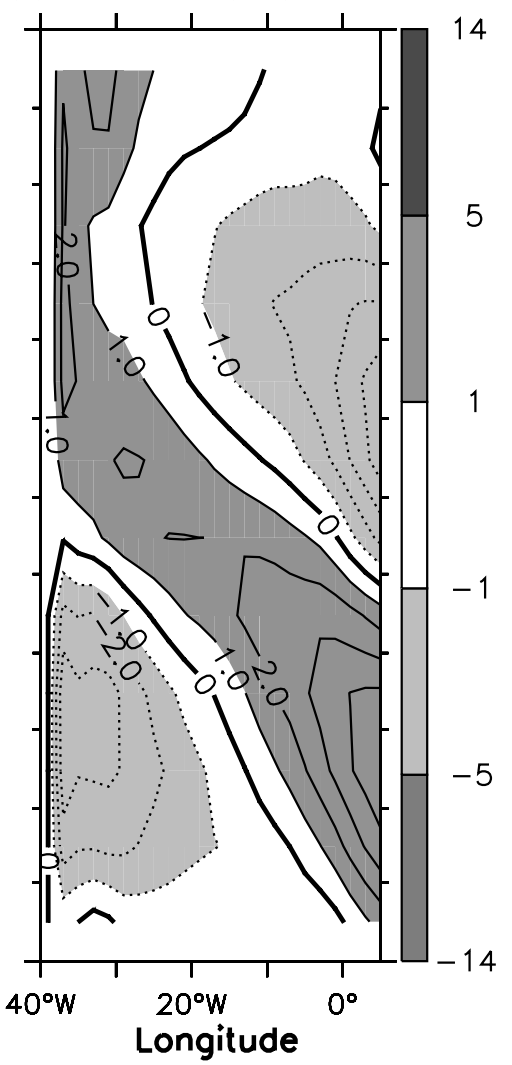

Figure 4. Seasonal cycle in SSH simulated by the MPI-OM and IOM at (a and d) the equator, (b and e) $4^{\circ} \mathrm{N}$, and ( $\mathrm{c}$ and $\left.\mathrm{f}\right) 4^{\circ} \mathrm{S}$. Anomalies with respect to the annual mean are shown with contours as in Figure 2. 
(a) MPI-OM U (ON)

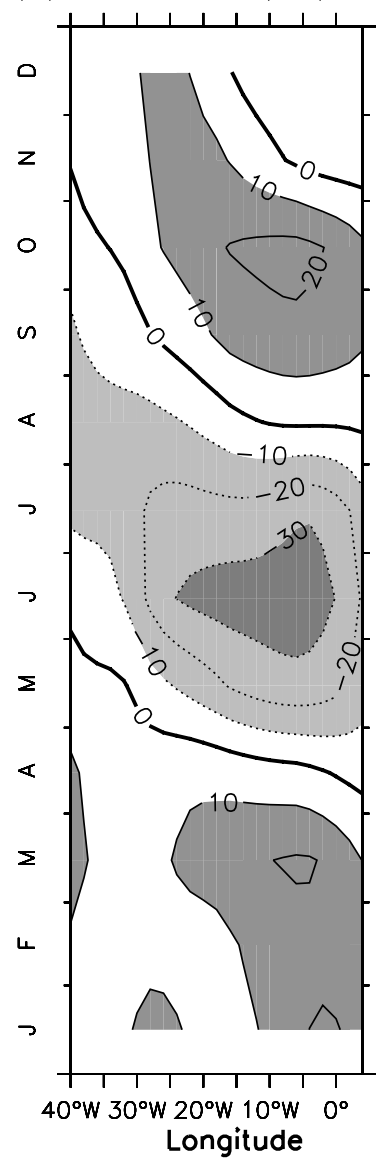

(b) IOM Total U (ON)

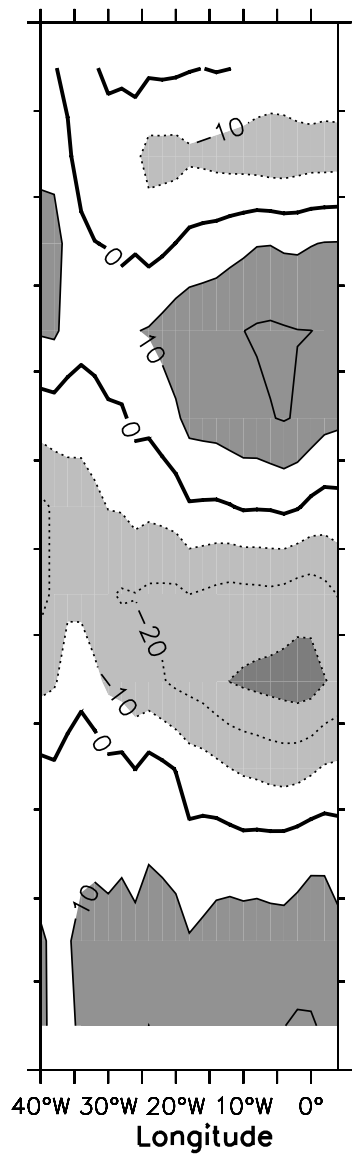

(c) IOM Linear U (ON)

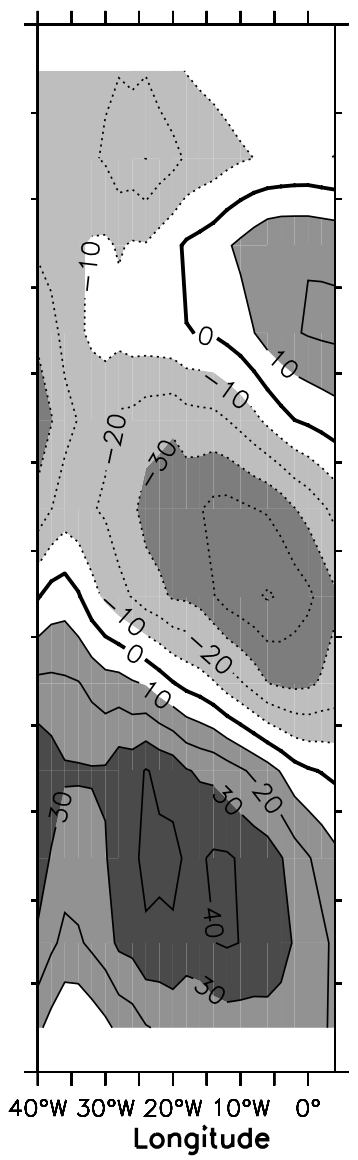

(d) IOM Nonlinear U (ON)

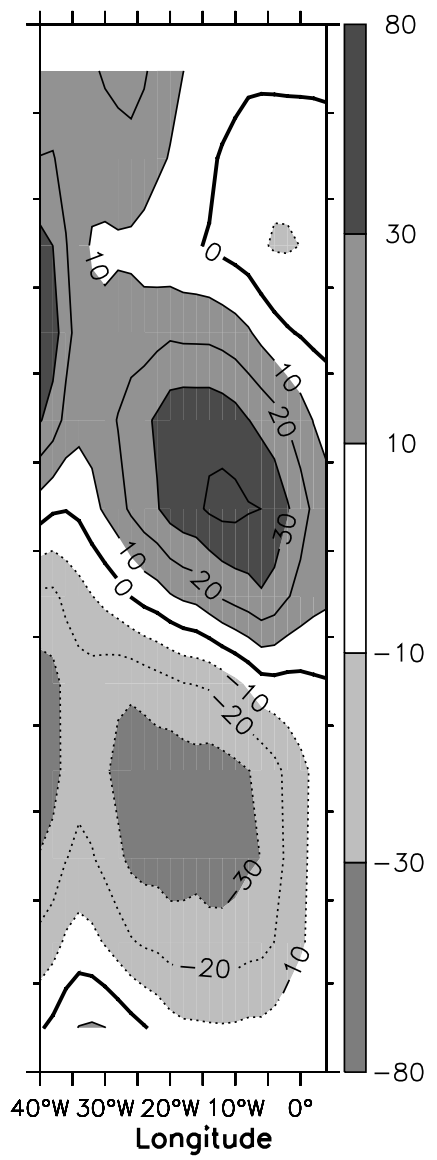

Figure 5. Simulated seasonal cycle of surface zonal currents at the equator for (a) MPI-OM, (b) IOM total, (c) IOM linear, and (d) IOM nonlinear components. Anomalies with respect to the annual mean are shown with contours as in Figure $1 \mathrm{~h}$.

and vertical advection, while vertical diffusion dissipates nonlinear velocity. Meridional advection, which is related to variations in both meridional currents and meridional variation of zonal currents, is strong (weak) from June to October (January-May). Vertical advection is controlled by changes in upwelling, which follow changes in zonal wind (Figure 1b). In boreal summer, for example, when upwelling is stronger following the intensification of the surface trades, vertical advection of momentum brings more eastward momentum to the surface layer and reduces the westward momentum. This is consistent with Philander and Pacanowski [1980].

[23] To better understand the linear solution, it is decomposed into (vertical) baroclinic modes, Kelvin and Rossby waves, and contributions from eastern and western boundary reflections. The seasonal cycle of SSH and surface zonal currents in the linear solution is determined primarily by the first four baroclinic modes (not shown). For SSH, the second mode is dominant, but for surface currents the second and third ones are most important. These results are consistent with previous studies [ $d u$ Penhoat and Treguier, 1985; Illig et al., 2004; Thierry et al., 2004; Brandt and Eden, 2005].

[24] The wind forced meridional mode model, which includes only the first four baroclinic modes, and the Kelvin and first meridional mode Rossby waves, is able to repro- duce the essential features of the seasonal cycle in $\mathrm{SSH}$ (Figure 7a). At the equator, the eastward propagation of sea level occurring between January and August is captured. As are the more rapidly eastward propagating, basin wide $\mathrm{SSH}$ anomalies that occur in September and October. The contribution of Kelvin (Figure 7b) and Rossby (Figure 7c) waves to the solution is comparable in the west, but in the east the Kelvin wave contribution is about three times larger. The Kelvin wave component (Figure 7b) gives rise to the eastward propagation in SSH. At eastern and western boundaries, Kelvin and Rossby wave contributions are in phase with each other, indicating the importance of boundary reflections [Schouten et al., 2005]. There are some differences between simulated and observed SSH variations. For example, at the end of the year in the east, a negative signal is simulated, while a positive one is observed. Simulated variability in the west is also stronger than observed.

[25] For surface zonal currents at the equator, the meridional mode model (Figure $7 \mathrm{~d}$ ) essentially reproduces the results of the linear component of the IOM (Figure 5c). The Kelvin (Rossby) wave zonal currents anomaly is, by definition, proportional to the Kelvin (Rossby) wave $\mathrm{SSH}$ anomaly. However, the Rossby wave contribution (Figure $7 \mathrm{f}$ ) is now greater than that of the Kelvin wave (Figure 7e). This is because at the equator the first meridional Rossby 
(a) UU (ON)

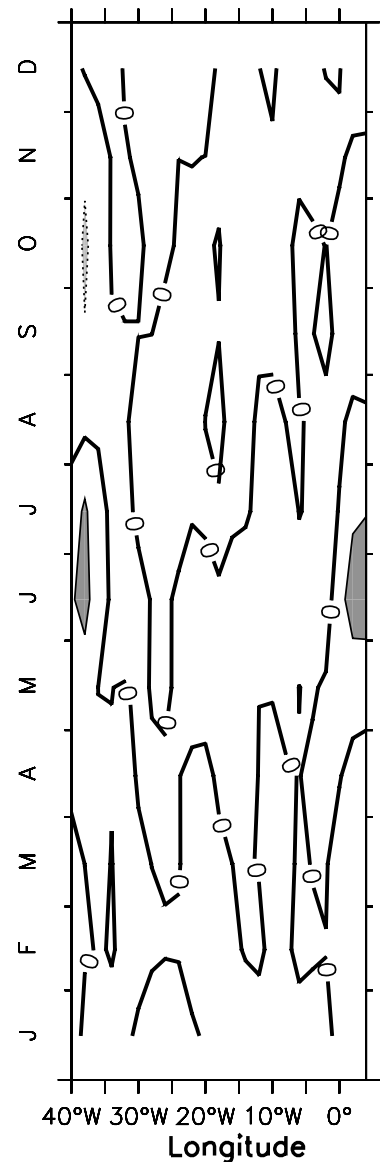

(b) VU (ON)

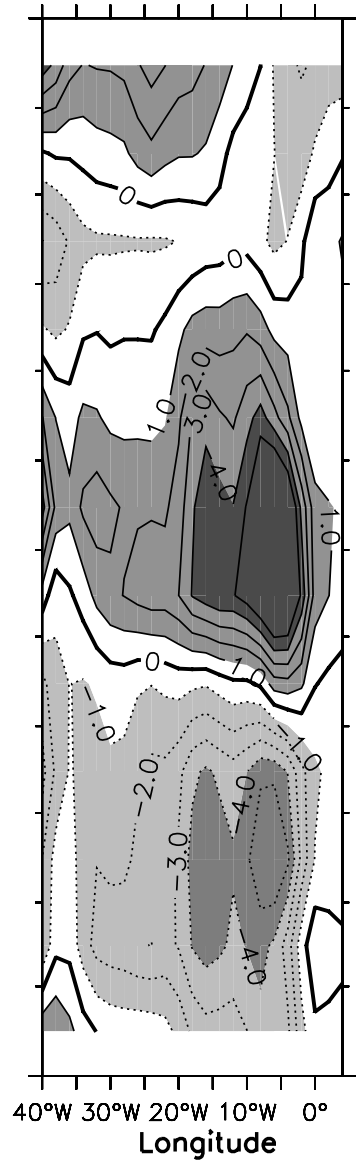

(c) WU (ON)

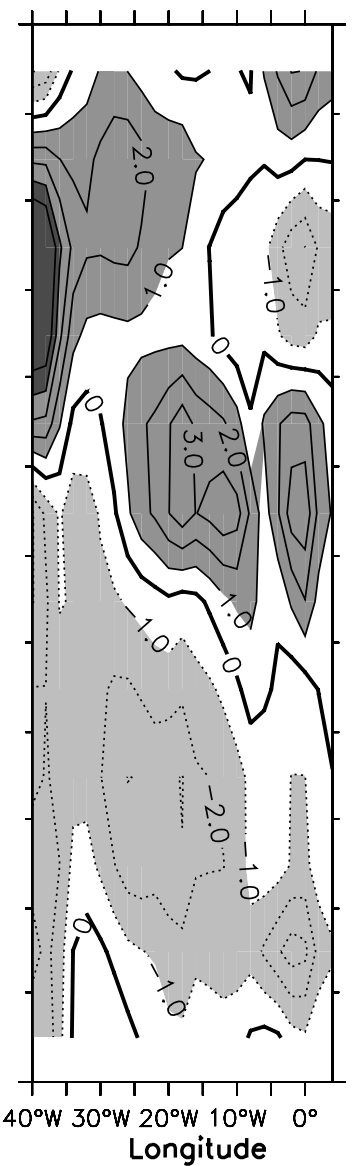

(d) kUzz (ON)

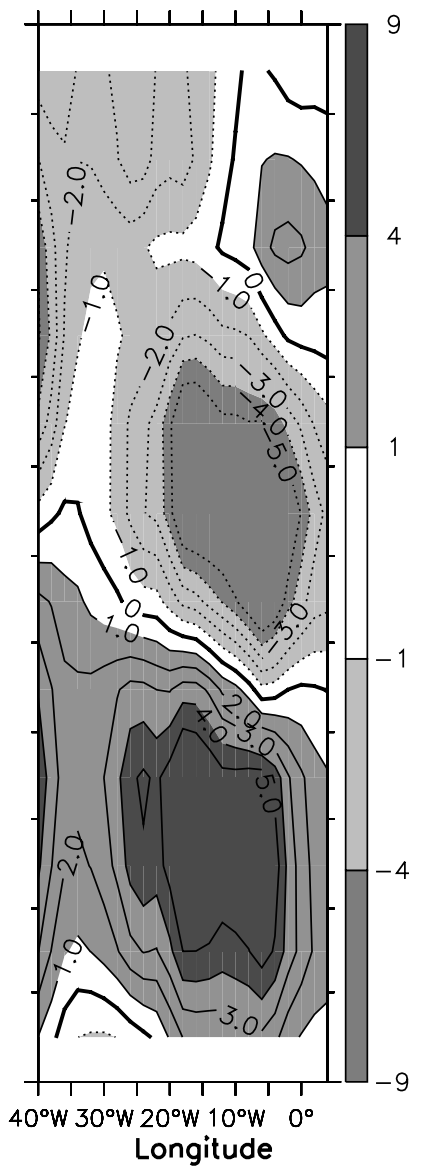

Figure 6. Seasonal cycle of the zonal momentum budget of the nonlinear component of the IOM for (a) zonal advection, (b) meridional advection, (c) vertical advection, and (d) sum of vertical and horizontal diffusion of zonal momentum. The contour interval is $10^{-5} \mathrm{~cm} \mathrm{~s}^{-2}$.

wave contributes proportionally more to surface zonal currents than SSH anomalies [e.g., Gill, 1982]. Thus, the Rossby wave contribution (also forced by westward propagating zonal wind stress) gives rise to the westward propagation in surface zonal currents at the equator. $Y u$ and McPhaden [1999] reached a similar conclusion for the Pacific.

[26] At $4^{\circ} \mathrm{S}$ and $4^{\circ} \mathrm{N}$, the amplitude of the second baroclinic mode Kelvin wave is only $20 \%$ of its equator maximum. Thus at these latitudes, Rossby waves dominate. The Rossby wave component (Figure 7c) for SSH resembles the average variations of observed SSH at $4^{\circ} \mathrm{S}$ and $4^{\circ} \mathrm{N}$ (not shown), which mainly result from meridionally symmetric long Rossby waves. Thus, the first meridional mode Rossby waves explain the westward propagation in observed sea level at these latitudes.

[27] The contribution of Kelvin and Rossby wave reflections at the eastern and western boundaries to the equatorial SSH and surface zonal currents variability is computed by the model (Figure 8). Their contribution to the seasonal cycle of simulated SSH and surface zonal currents at the equator equals that of the wind forced waves (not shown). This is consistent with previous studies [Philander and Pacanowski, 1986; Schouten et al., 2005]. This is in contrast to the Pacific, where boundary reflections are not important [e.g., Yu and McPhaden, 1999].
[28] As shown above, the seasonal cycle exhibits a strong semiannual cycle and has features of the classical basin mode, whereas the dominant wind forcing is annual (Figures 9a and 9b). The free oscillation (basin mode) of the second baroclinic mode has a period of 220 days [Cane and Moore, 1981]. To investigate whether it is excited and may explain these observed features, the meridional mode model was forced separately with annual (Figure 9a) and semiannual (Figure 9b) wind components. SSH and surface currents generated by the semiannual wind forcing (Figures 9d and 9f) are similar in amplitude to those generated by the annual forcing (Figures 9c and 9e). They also display the essential features of the basin mode: zonal SSH gradient and surface zonal current variations that are $90^{\circ}$ out of phase. From March-August (SeptemberFebruary) the semiannual and annual components constructively (destructively) interfere and the basin mode features are most (less) prominent in observations.

[29] We further investigate the contributions of windforced waves (Figures 10a and 10c) and waves generated by boundary reflections (Figures 10b, 10d) to sea level for semiannual (upper) and annual (lower) components, respectively. The direct response to the semiannual component of wind stress is much weaker than that to annual component. Boundary reflections enhance (partly cancel) the responses 
(a) SSH (ON) sum

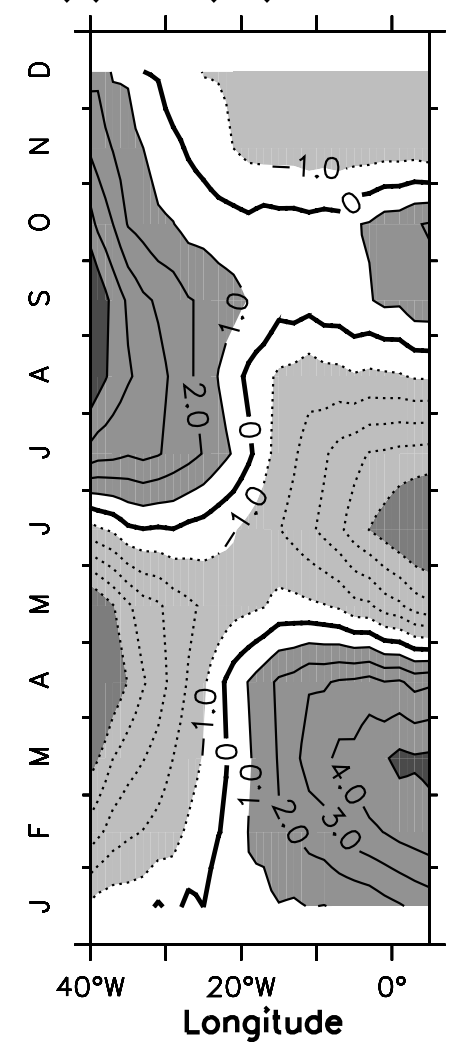

(d) U (ON) sum

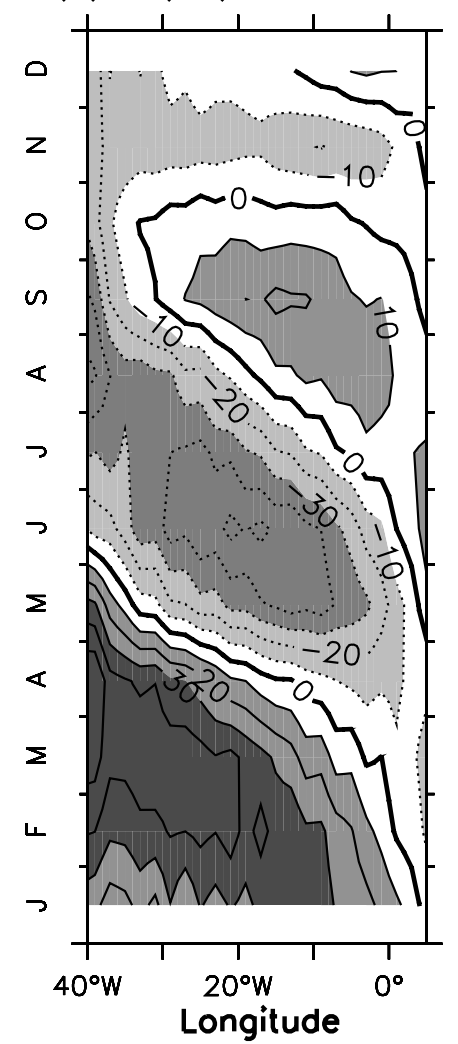

(b) SSH (ON) Kelvin

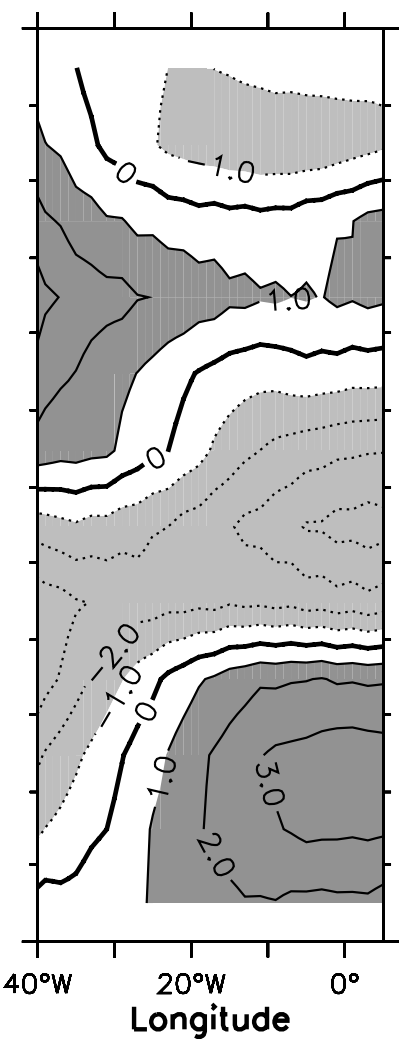

(e) U (ON) Kelvin

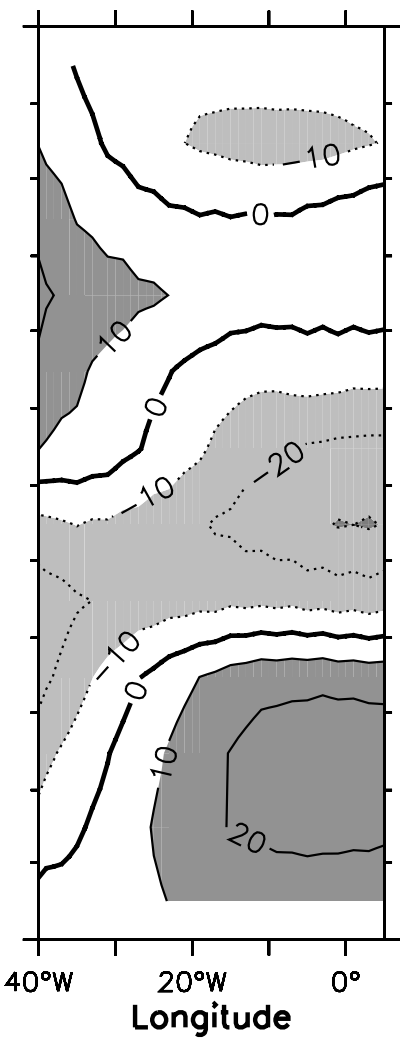

(c) SSH (ON) $1^{\text {st Rossby }}$

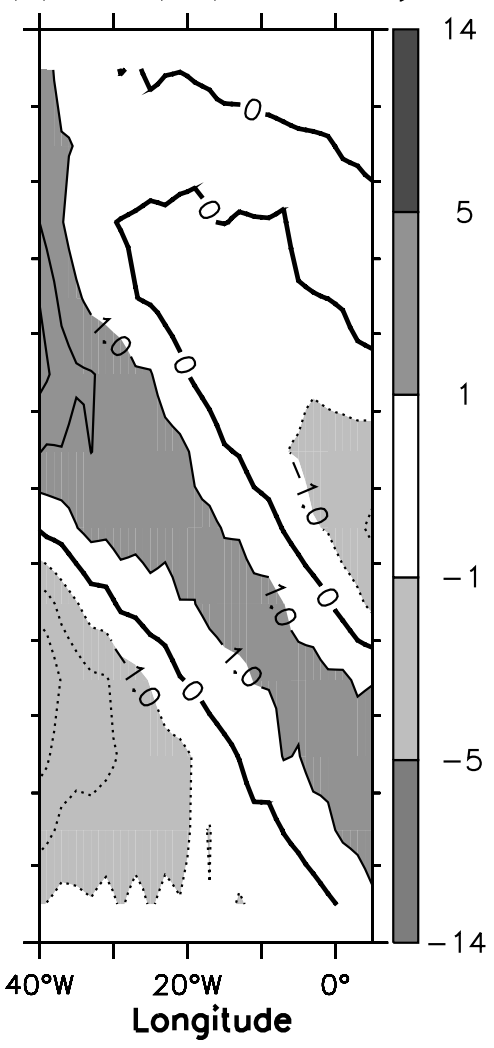

(f) U (ON) $1^{\text {st }}$ Rossby

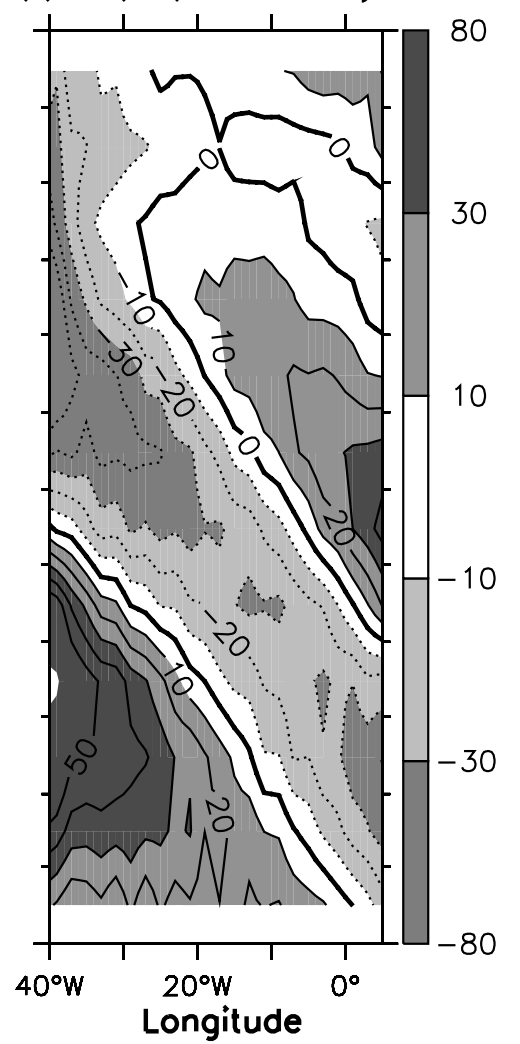

Figure 7. The contribution of (a and d) the sum of Kelvin and 1st Rossby waves, (b and e) Kelvin waves, and (c and f) 1st Rossby waves to the seasonal cycle of SSH (Figures 7a-7c) and surface zonal currents (Figures $7 \mathrm{~d}-7 \mathrm{f}$ ) at the equator. Contour of SSH and surface zonal currents are as in Figures 2 and 1 , respectively. 
(a) SSH (ON) sum

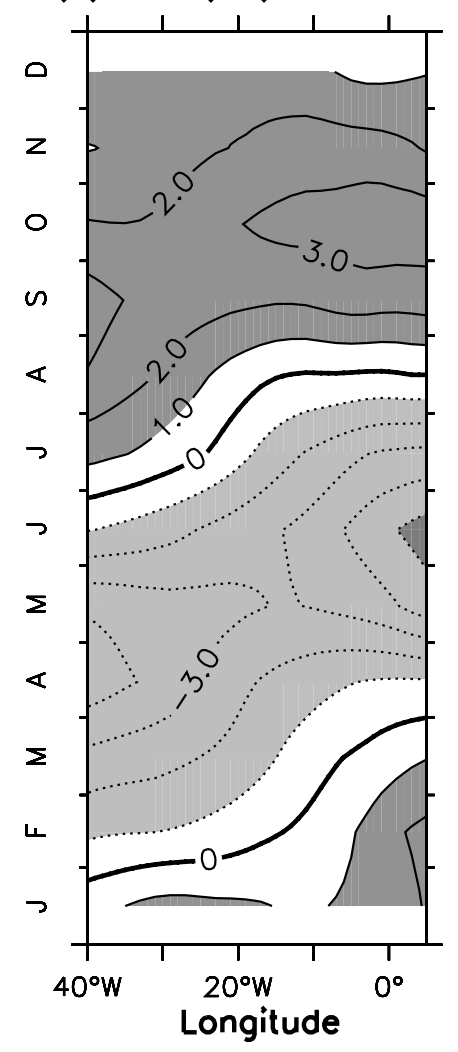

(d) U (ON) sum

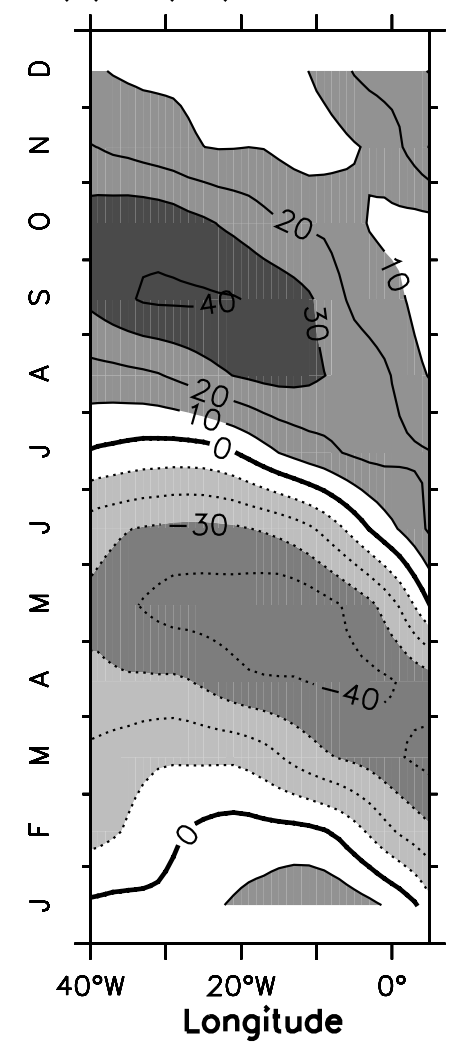

(b) SSH (ON) Kelvin

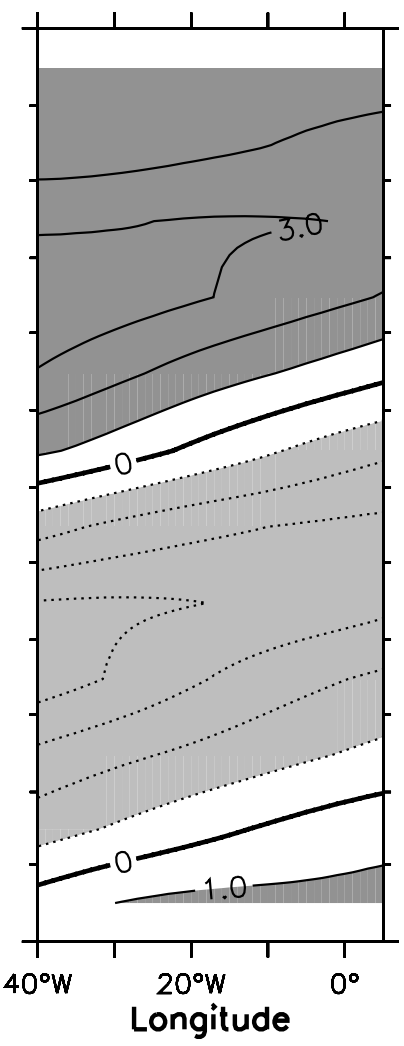

(e) U (ON) Kelvin

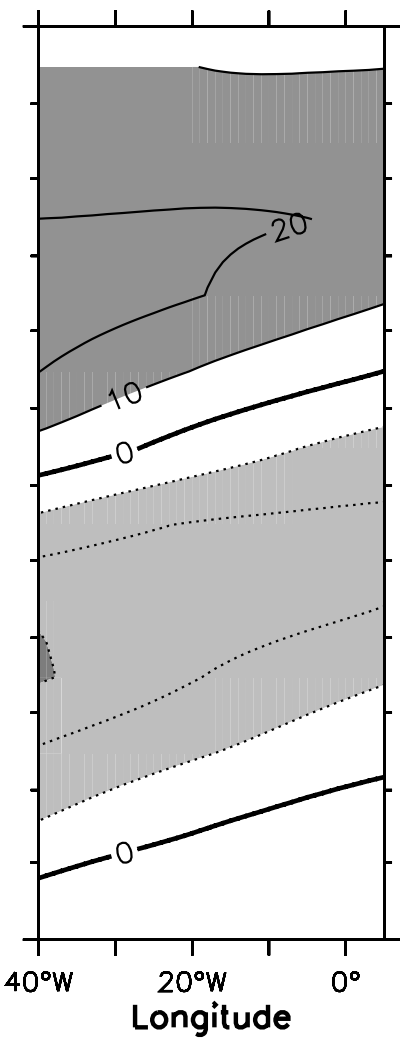

(c) SSH (ON) $1^{\text {st }}$ Rossby

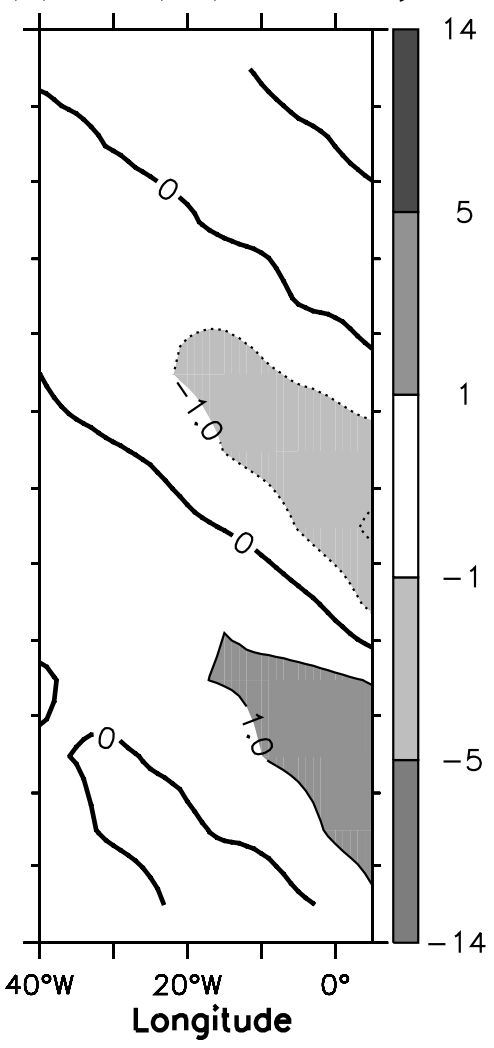

(f) U (ON) $1^{\text {st }}$ Rossby

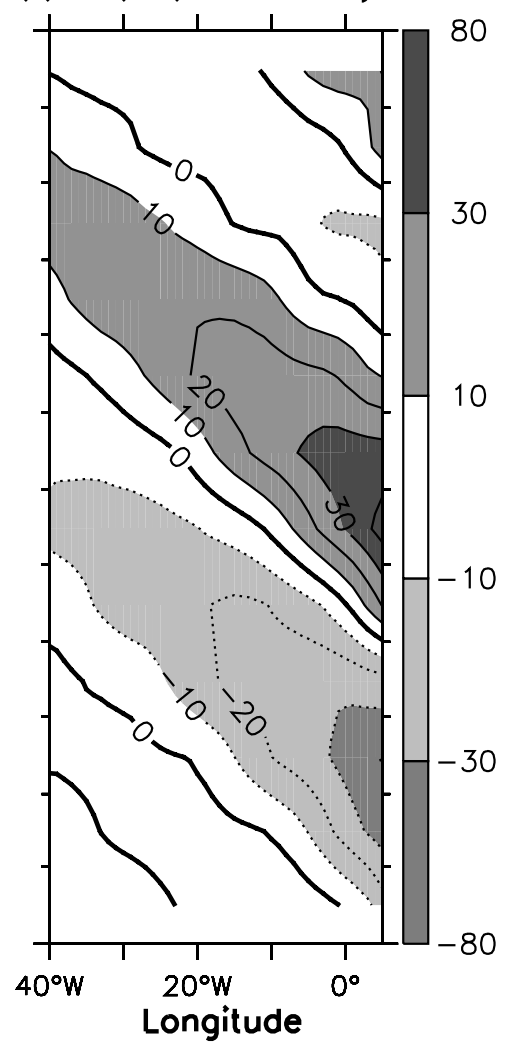

Figure 8. Contribution of boundary reflections to seasonal cycle of $(a-c) S S H$ and $(d-f)$ surface zonal currents at the equator as decomposed into the sum of Kelvin and 1st Rossby waves (Figures 8a and 8d), Kelvin waves (Figures 7b and 7e), and 1st Rossby waves (Figures 7c and 7f). Contour of SSH and surface zonal currents are as in Figures 2 and 1, respectively. 
(o) Annual toux (ON)

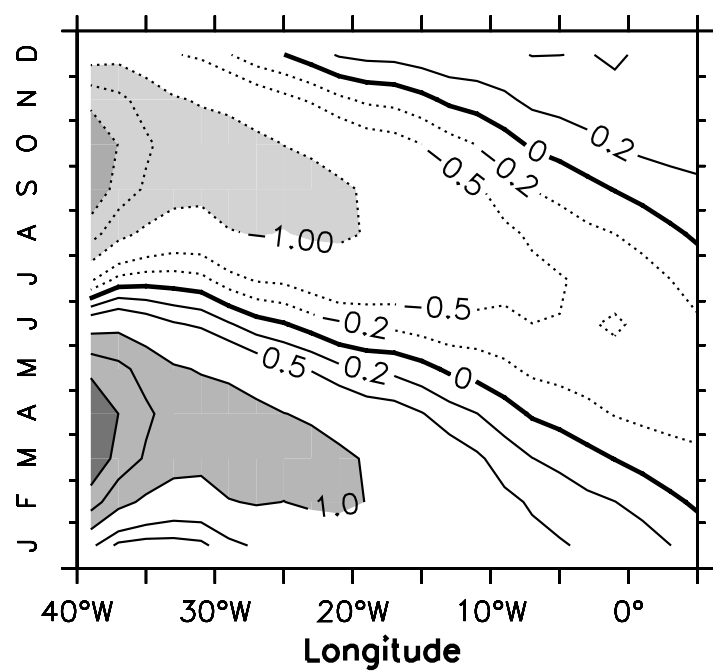

(c) Annual SSH (ON)

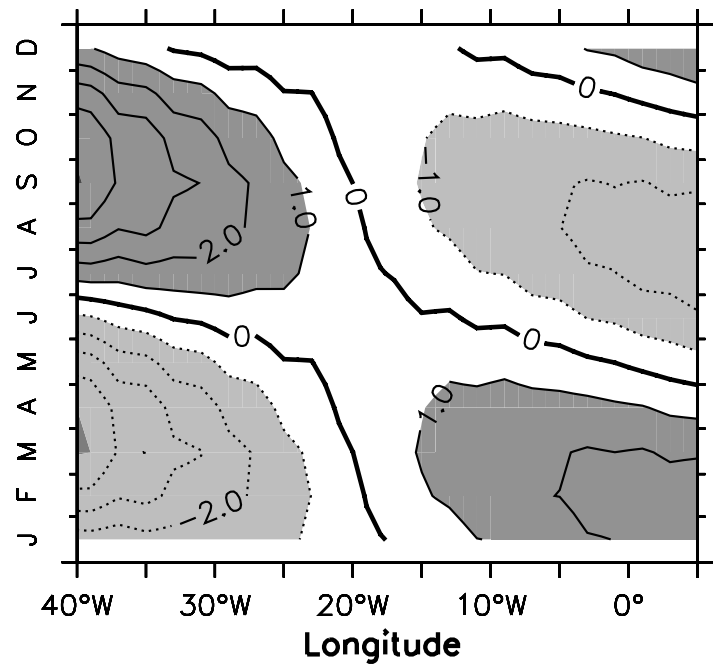

(e) Annual U (ON)

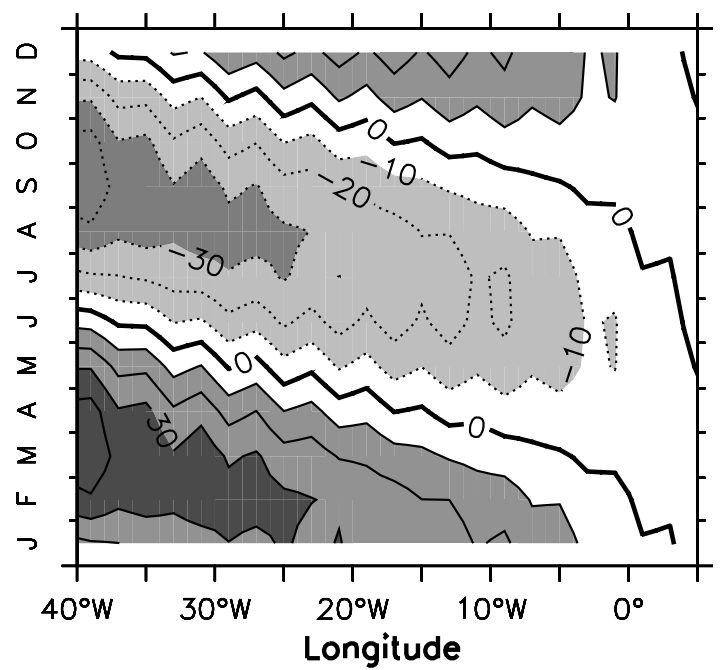

(b) Semi-annual taux (ON)

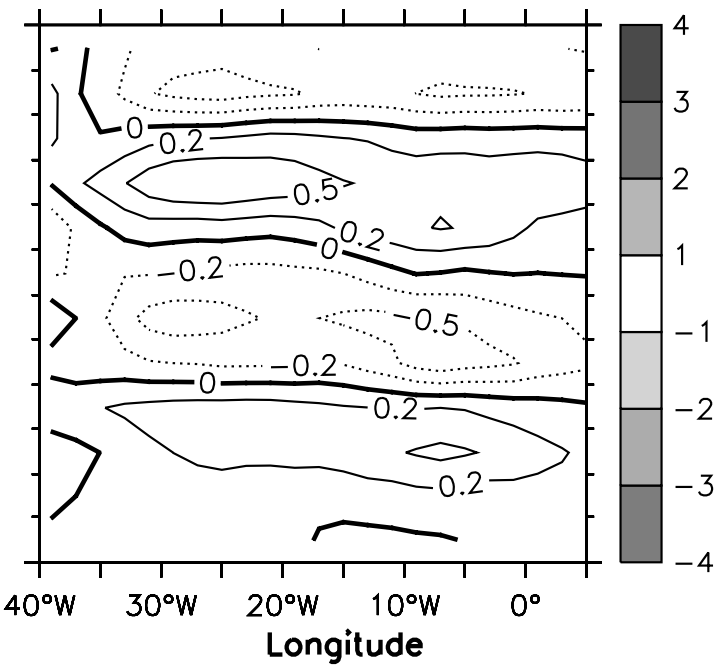

(d) Semi-onnual SSH (ON)

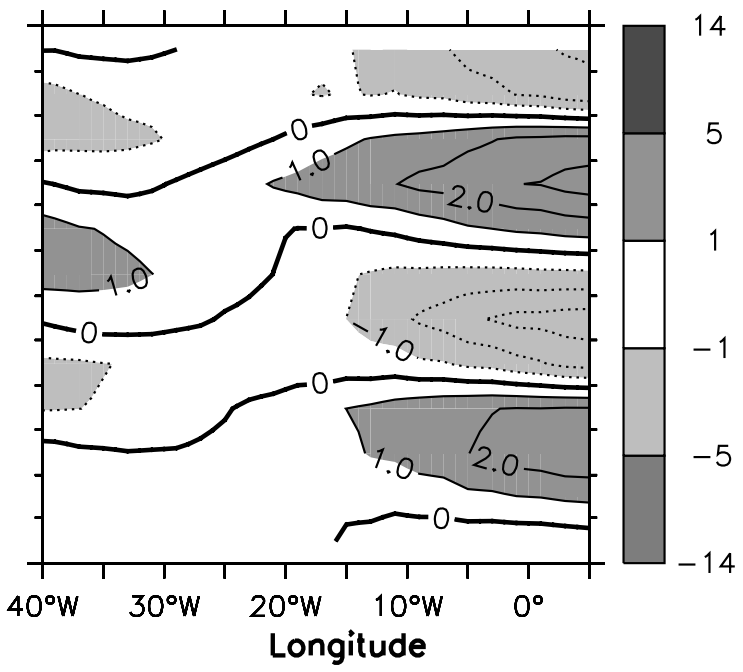

(f) Semi-onnual U (ON)

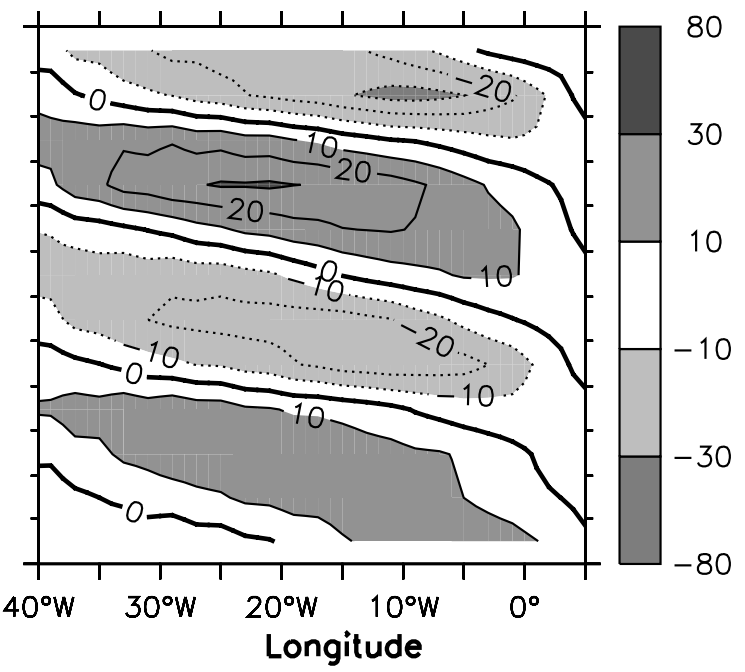

Figure 9. (a) Annual harmonic and (b) residual semiannual components of NCEP/NCAR zonal wind stress [Kalnay et al., 1996] and the corresponding (c and d) SSH and (e and f) surface zonal current, as generated by the Kelvin and 1st Meridional Rossby waves. Contour interval of zonal wind stress (Figures 9a and 9b) is $0.5 \times 10^{-2} \mathrm{~N} \mathrm{~m}^{-2}$, with additional contours $-0.2 \times 10^{-2} \mathrm{~N} \mathrm{~m}^{-2}$ and $0.2 \times$ $10^{-2} \mathrm{~N} \mathrm{~m}^{-2}$. Contour interval of SSH (surface zonal currents) is $1 \mathrm{~cm}\left(10 \mathrm{~cm} \mathrm{~s}^{-1}\right)$. 
(a) Semi-annual forced (ON)

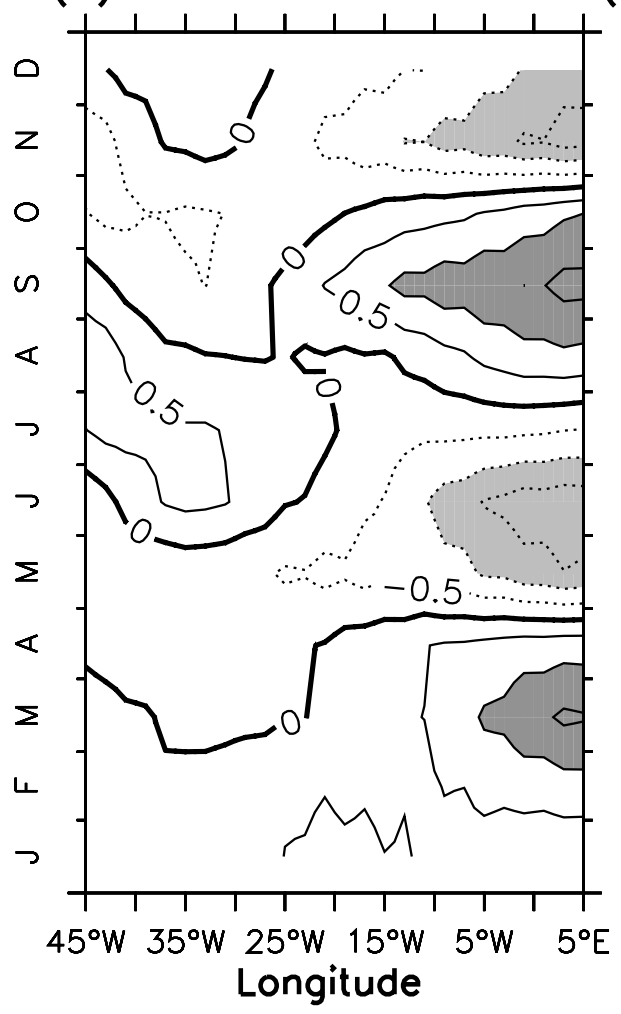

(c) Annual forced (ON)

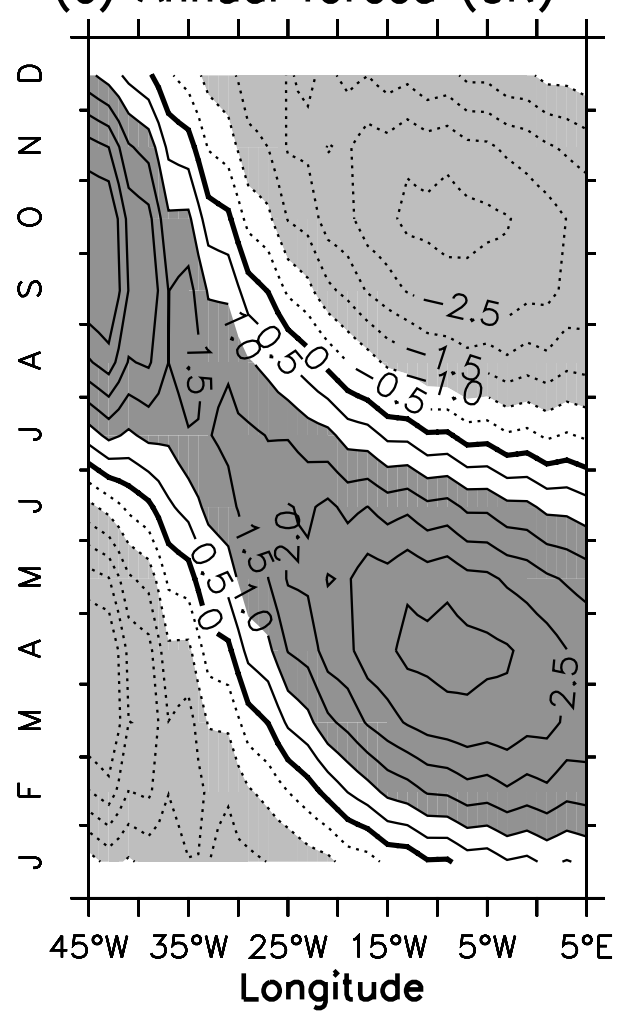

(b) Semi-annual reflected (ON)

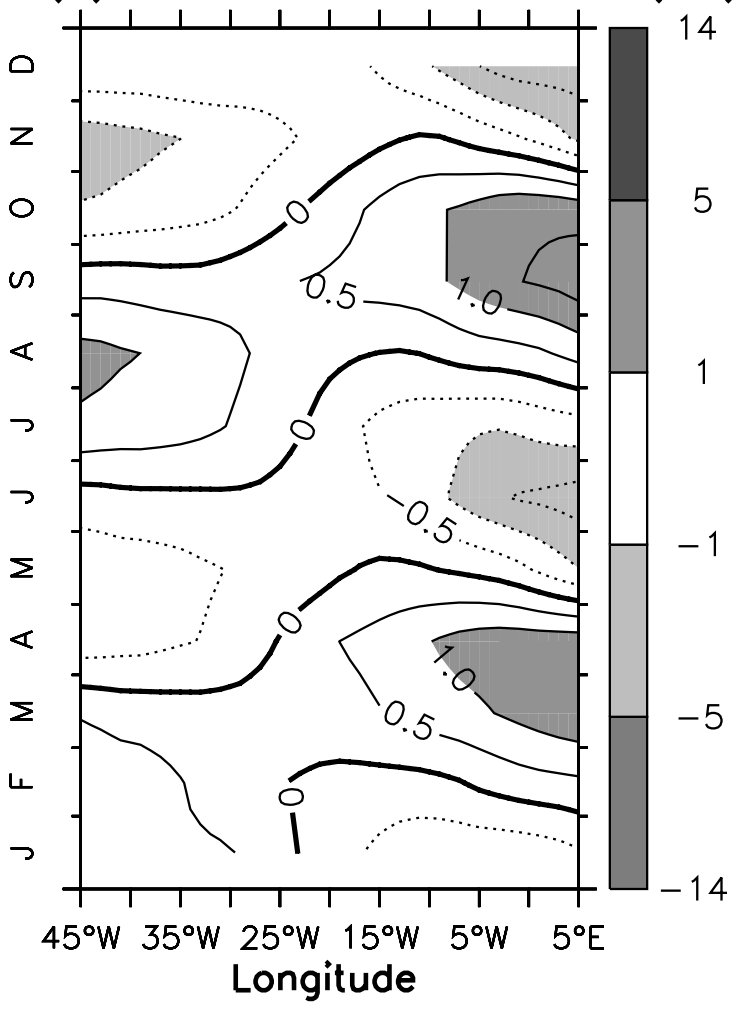

(d) Annual reflected (ON)

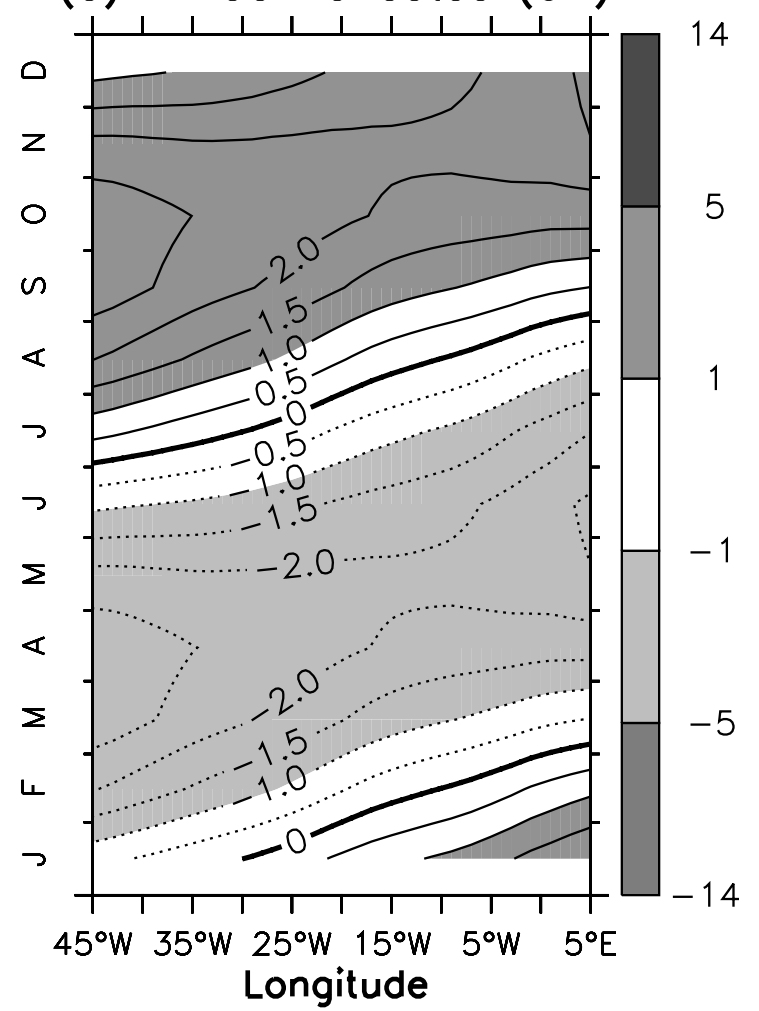

Figure 10. (a and c) Contribution of wind-forced waves and (b and d) waves generated by boundary reflections to SSH for semiannual (Figures 10a and 10b) and annual (Figures 10c and 10d) zonal wind stress. Contour interval is $0.5 \mathrm{~cm}$. 
to the semiannual (annual) component of wind stress so that total semiannual component (Figure 9d) of sea level is comparable with annual component (Figure 9c). Thus, the free oscillation of second baroclinic mode appears responsible for the strong semiannual cycle, despite a weak semiannual wind forcing.

\section{Discussions and Conclusions}

[30] In this study, the seasonal cycle of surface wind, SST, $\mathrm{SSH}$ and surface zonal currents were first described using in situ and satellite observations and atmospheric reanalysis primarily between 1993 and 2007. Seasonal variations in thermocline depth and sea level display prominent annual and semiannual cycles in the west and east, respectively. At the equator, variations propagate eastward, but westward at $4^{\circ} \mathrm{N}$ and $4^{\circ} \mathrm{S}$. Surface zonal currents at the equator exhibit a dominant semiannual cycle with westward propagation. This description is consistent with previous studies and corroborated by other climatologies.

[31] Although the seasonal cycle in the equatorial Atlantic has received much attention, several aspects remain debated. Here three of these are addressed, using an OGCM, an intermediate ocean model (IOM) and a linear meridional mode model. First, what is the origin of the east-west propagation characteristics in SSH and zonal currents. The modelling results here show that linear dynamics can explain the phase and propagation characteristics in the seasonal variation of sea level and also get key features of surface zonal current variations. The linear solution is essentially reproduced by the first four baroclinic modes, although the second and third are dominant. Only the Kelvin and first meridional mode Rossby waves are required, with boundary reflected waves contributing as strongly as directly forced waves. For SSH at the equator, both Kelvin and Rossby wave contributions are significant, but the Kelvin wave contribution dominates and results in eastward propagation. At $4^{\circ} \mathrm{N}$ and $4^{\circ} \mathrm{S}$, Rossby waves dominate variability and give rise to westward propagation. For surface zonal currents at the equator, the Rossby wave contribution is larger than that of the Kelvin wave, explaining the observed westward propagation. The coincidence of integrating characteristics of Rossby waves with westward propagating zonal wind stress enhances the westward propagating signal, consistent with Weisberg and Tang [1983]. However, Rossby waves related to the stationary semiannual component of zonal wind stress and resulting mainly from eastern boundary reflections also contribute.

[32] These results in many respects are not entirely new, being based in essence on the well established importance of long, nondispersive Kelvin and Rossby waves [Cane and Sarachik, 1981]. However, they provide a clear decomposition of the dynamics using modern forcing data. Schouten et al. [2005] found that sea level variations have the same westward phase speed as the first meridional mode Rossby of the second baroclinic mode at $4^{\circ} \mathrm{N}$ and $4^{\circ} \mathrm{S}$. They are reflected as a Kelvin wave on the western boundary and propagate eastward through the whole basin in September and October at the equator. The modelling results here strongly support their arguments. Bunge and Clarke [2009] found that eastward propagation of sea level from April to July at the equator is too slow compared to theoretical phase speeds of Kelvin waves of the first few baroclinic modes. They did not consider variations in September and October, nor did they find eastward propagation in zonal wind stress. Therefore, they excluded equatorial waves as an explanation [Schouten et al., 2005]. However, modelling results here show that Kelvin and Rossby waves are both important at the equator. Additionally, the contributions of boundary reflections equal that of the wind-forced response. As a result of these factors, it is not possible to interpret the propagation speed in terms of single forced Kelvin wave [Cane and Sarachik, 1981].

[33] The second aspect addressed was the role of nonlinearity in the seasonal cycle of surface zonal currents at the equator. Although linear theory can explain the phase and east-west propagation of the latter, variations are far too strong. Here, nonlinear terms were shown to weaken the variability to observed levels, and improve its phase and zonal extent. The most significant terms are meridional advection, vertical diffusion, and vertical advection; zonal advection is negligible. Meridional and vertical advection drive changes in the nonlinear velocity. Vertical diffusion dissipates nonlinear velocity. In particular, vertical advection of momentum brings more eastward momentum to the surface layer and reduces the westward momentum in the cold tongue when upwelling is stronger in boreal summer. These results clarify the cause of deficiencies in linear models [du Penhoat and Treguier, 1985] and the importance of nonlinearity [Philander and Pacanowski, 1980].

[34] The third aspect investigated was the prominence of the semiannual cycle in SSH and surface zonal currents that is unexpected given the dominance of the annual cycle in surface winds. Modelling results indicate that this occurs because the semiannual cycle in surface winds resonantly excites the second baroclinic mode's basin mode. The basin mode (schematic in Figure 11) is a free solution of equatorial ocean dynamics [Cane and Moore, 1981]. The period is set by the time it takes a disturbance to circuit the basin, and hence is dependent on the wave speed and basin size. For the second baroclinic mode in the Atlantic it is about 220 days, which is approximately semiannual. Thus, the semiannual component in zonal wind stress, although much weaker than the annual component, is able to force a strong semiannual cycle in SSH and surface currents. The result also explains why characteristic features of the basin mode features are apparent in the observed seasonal cycle. While a similar argument was given to explain the semiannual signal in the deep tropical Atlantic [Thierry et al., 2004], the role of the basin mode at the surface has not been previously recognized.

[35] The results here were drawn from three models, which of course have deficiencies. For example, sea level variability, especially at $4^{\circ} \mathrm{N}$, is slightly underestimated and not always in exact phase with observations in both the IOM and OGCM. In addition, the models used here are all low resolution and do not capture Tropical Instability Waves, which are important in the Tropical Atlantic [von Schuckmann et al., 2008]. However, the models used here are able to reproduce the key features of the observations, providing confidence in our results.

[36] The results here have several interesting implications. First, they imply that although the seasonal cycle of 


\section{Schematic of the basin mode}

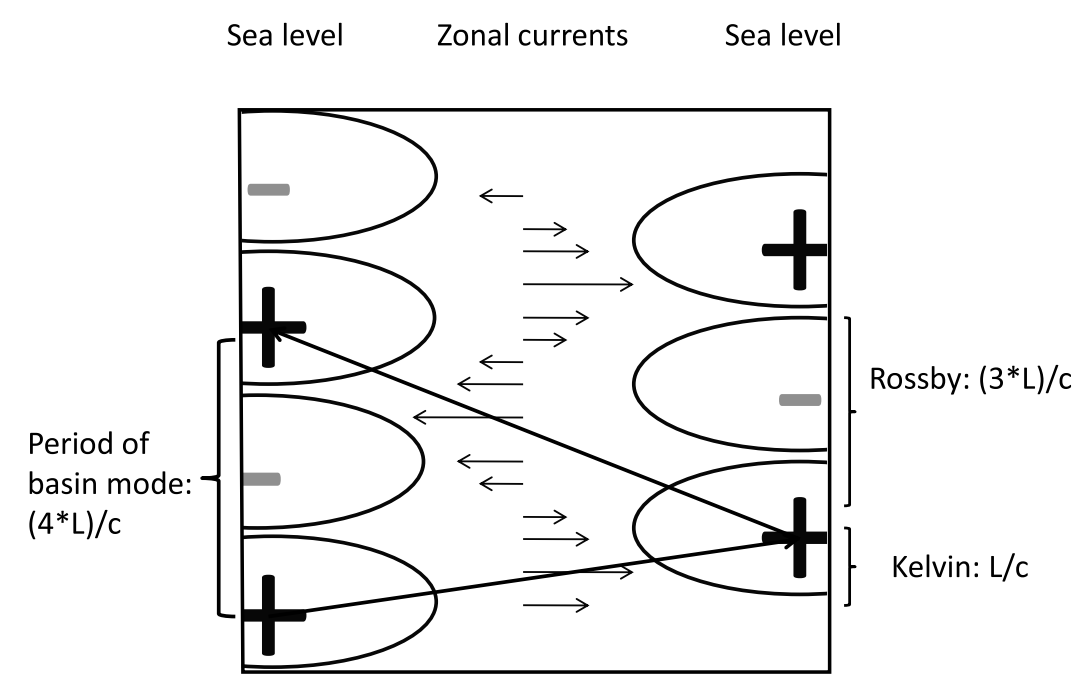

Basin width: L, phase speed: $c$

Figure 11. Schematic illustrating the basin mode [Cane and Moore, 1981].

SST in the equatorial Atlantic and Pacific are similar, the dynamics are likely very different. In particular, previous suggestions that the seasonal cycle in SST in the Atlantic results from a coupled atmosphere mixed layer SST mode not involving thermocline variations [Chang and Philander, 1994; Xie, 1994]. However, the seasonal relationship among SST, thermocline depth, and surface zonal currents in the Atlantic appear more consistent with a thermocline mode. This difference maybe partly due to the different basin sizes. A different mechanism for the seasonal cycle in SST in the Atlantic has implications for the interaction of the seasonal cycle with interannual variability, and hence deserves further attention.

[37] Acknowledgments. We thank Stephane Raynaud for providing the latest version of the IOM and Peter Brandt and Verena Hormann for fruitful discussions. The work was supported by the European Union AMMA project, DFG Sonderforschungsbereich 754 project, and the German BMBF Nordatlantik project.

\section{References}

Adamec, D., and J. O'Brien (1978), The seasonal upwelling in the Gulf of Guinea due to remote forcing, J. Phys. Oceanogr., 8(6), 1050-1060, doi:10.1175/1520-0485(1978)008<1050:TSUITG >2.0.CO;2.

Antonov, J. I., R. A. Locarnini, T. P. Boyer, A. V. Mishonov, H. E. Garcia, and S. Levitus (2006), World Ocean Atlas 2005, vol. 2, Salinity, NOAA Atlas NESDIS, vol. 62, NOAA, Silver Spring, Md.

Arnault, S., B. Bourlès, Y. Gouriou, and R. Chuchla (1999), Intercomparison of the upper layer circulation of the western equatorial Atlantic Ocean: In situ and satellite data, J. Geophys. Res., 104(C9), 21,17121,194, doi:10.1029/1999JC900124.

Bonjean, F., and G. Lagerloef (2002), Diagnostic model and analysis of the surface currents in the tropical Pacific Ocean, J. Phys. Oceanogr., 32(10), 2938-2954, doi:10.1175/1520-0485(2002)032<2938:DMAAOT $>2.0$. $\mathrm{CO} ; 2$.

Brandt, P., and C. Eden (2005), Annual cycle and interannual variability of the mid-depth tropical Atlantic Ocean, Deep Sea Res. Part I, 52(2), 199-219, doi:10.1016/j.dsr.2004.03.011.

Bunge, L., and A. Clarke (2009), Seasonal propagation of sea level along the equator in the Atlantic, J. Phys. Oceanogr., 39(4), 1069-1074, doi:10.1175/2008JPO4003.1.
Busalacchi, A., and J. Picaut (1983), Seasonal variability from a model of the tropical Atlantic Ocean, J. Phys. Oceanogr., 13(9), 1564-1588, doi:10.1175/1520-0485(1983)013<1564:SVFAMO>2.0.CO;2.

Cane, M., and D. Moore (1981), A note on low-frequency equatorial basin modes, J. Phys. Oceanogr., 11(11), 1578-1584, doi:10.1175/15200485(1981)011<1578:ANOLFE>2.0.CO;2.

Cane, M., and E. Sarachik (1981), The response of a linear baroclinic equatorial ocean to periodic forcing, J. Mar. Res., 39, 651-693.

Chang, P., and S. G. Philander (1994), A coupled ocean-atmosphere instability of relevance to the seasonal cycle, J. Atmos. Sci., 5l(24), 3627-3648, doi:10.1175/1520-0469(1994)051<3627:ACOIOR $>2.0$. $\mathrm{CO} ; 2$.

Chang, P., L. Ji, B. Wang, and T. Li (1995), Interactions between the seasonal cycle and El Ni no-Southern Oscillation in an intermediate coupled ocean-atmosphere model, J. Atmos. Sci., 52(13), 2353-2372, doi:10.1175/1520-0469(1995)052<2353:IBTSCA >2.0.CO;2.

du Penhoat, Y., and Y. Gouriou (1987), Hindcasts of equatorial sea surface dynamic height in the Atlantic in 1982-1984, J. Geophys. Res., 92, $3729-3740$.

du Penhoat, Y., and A. Treguier (1985), The seasonal linear response of the tropical Atlantic ocean, J. Phys. Oceanogr., 15(3), 316-329, doi:10.1175/1520-0485(1985)015.

Foltz, G., S. Grodsky, J. Carton, and M. McPhaden (2003), Seasonal mixed layer heat budget of the tropical Atlantic Ocean, J. Geophys. Res. 108(C5), 3146, doi:10.1029/2002JC001584.

Gent, P., K. O'Neill, and M. Cane (1983), A model of the semiannual oscillation in the equatorial Indian Ocean, J. Phys. Oceanogr., 13(12), 2148-2160, doi:10.1175/1520-0485(1983)013<2148:AMOTSO $>2.0$. $\mathrm{CO} ; 2$.

Gill, A. E. (1982), Atmosphere-Ocean Dynamics, Int. Geophys. Ser., vol. 30, 662 pp., Acad. Press, New York.

Gill, A. E., and A. J. Clarke (1974), Wind-induced upwelling, coastal currents and sea-level changes, Deep Sea Res., 21, 325-345.

Houghton, R. (1983), Seasonal variations of the subsurface thermal structure in the Gulf of Guinea, J. Phys. Oceanogr., 13(11), 2070-2081, doi:10.1175/1520-0485(1983)013<2070:SVOTST>2.0.CO;2.

Illig, S., B. Dewitte, N. Ayoub, Y. du Penhoat, G. Reverdin, P. De Mey, F. Bonjean, and G. Lagerloef (2004), Interannual long equatorial waves in the tropical Atlantic from a high-resolution ocean general circulation model experiment in 1981-2000, J. Geophys. Res., 109(C2), C02022, doi:10.1029/2003JC001771.

Jin, F. (1997), An equatorial ocean recharge paradigm for ENSO. Part I: Conceptual model, J. Atmos. Sci., 54(7), 811-829, doi:10.1175/15200469(1997)054<0811:AEORPF $>2.0 . \mathrm{CO} ; 2$.

Kalnay, E., et al. (1996), The NCEP/NCAR 40-Year Reanalysis Project, Bull. Am. Meteorol. Soc., 77(3), 437-471, doi:10.1175/15200477(1996)077<0437:TNYRP>2.0.CO;2. 
Keenlyside, N., and R. Kleeman (2002), Annual cycle of equatorial zonal currents in the Pacific, J. Geophys. Res., 107(C8), 3093, doi:10.1029/ 2000JC000711.

Keenlyside, N., and M. Latif (2007), Understanding equatorial Atlantic interannual variability, J. Clim., 20(1), 131-142, doi:10.1175/ JCLI3992.1.

Keenlyside, N. S. (2001), Improved modeling of zonal currents and SST in the tropical Pacific, Ph.D. thesis, Monash Univ., Melbourne, Victoria, Australia.

Levitus, S., R. Burgett, and T. Boyer (1994), World Ocean Atlas 1994, vol. 3, Salinity, NOAA Atlas NESDID, vol. 3, 111 pp., NOAA, Silver Spring, Md.

Liu, Z. (2002), A simple model study of ENSO suppression by external periodic forcing, J. Clim., 15(9), 1088-1098, doi:10.1175/15200442(2002)015<1088:ASMSOE>2.0.CO;2.

Locarnini, R., A. Mishonov, J. Antonov, T. Boyer, and H. Garcia (2006), World Ocean Atlas 2005, vol. 1, Temperature, NOAA Atlas NESDIS, vol. 61, NOAA, Silver Spring, Md.

Lumpkin, R., and Z. Garraffo (2005), Evaluating the decomposition of tropical Atlantic drifter observations, J. Atmos. Oceanic Technol., 22(9), 1403-1415, doi:10.1175/JTECH1793.1.

Marsland, S., H. Haak, J. Jungclaus, M. Latif, and F. Roske (2003), The Max-Planck-Institute global ocean/sea ice model with orthogonal curvilinear coordinates, Ocean Modell., 5(2), 91-127, doi:10.1016/ S1463-5003(02)00015-X

McCreary, J. (1981), A linear stratified ocean model of the coastal undercurrent, Philos. Trans. R. Soc. London Ser. A, 302(1469), 385-413, doi:10.1098/rsta.1981.0176.

McPhaden, M., et al. (1998), The Tropical Ocean-Global Atmosphere observing system: A decade of progress, J. Geophys. Res., 103, $14,169-14,240$.

Molinari, R. (1983), Observations of near-surface currents and temperature in the central and western tropical Atlantic ocean, J. Geophys. Res., 88 , $4433-4438$

Philander, S., and R. Pacanowski (1980), The generation of equatorial currents, J. Geophys. Res., 85, 1123-1136.

Philander, S., and R. Pacanowski (1986), A model of the seasonal cycle in the tropical Atlantic Ocean, J. Geophys. Res., 91, 14,192-14,206.

Picaut, J. (1983), Propagation of the seasonal upwelling in the eastern equatorial Atlantic, J. Phys. Oceanogr., 13(1), 18-37, doi:10.1175/ 1520-0485(1983)013<0018:POTSUI>2.0.CO;2.

Reverdin, G., and M. McPhaden (1986), Near-surface current and temperature variability observed in the equatorial Atlantic from drifting buoys, J. Geophys. Res., 91, 6569-6581.

Reynolds, R. (1988), A real-time global sea surface temperature analysis, J. Clim., 1(1), 75-87, doi:10.1175/1520-0442(1988)001< 0075:ARTGSS $>2.0 . \mathrm{CO} ; 2$

Reynolds, R., and D. Marsico (1993), An improved real-time global sea surface temperature analysis, J. Clim., 6(1), 114-119, doi:10.1175/15200442(1993)006<0114:AIRTGS $>2.0 . \mathrm{CO} ; 2$

Reynolds, R., N. Rayner, T. Smith, D. Stokes, and W. Wang (2002), An improved in situ and satellite SST analysis for climate, J. Clim., 15(13), 1609-1625, doi:10.1175/1520-0442(2002)015<1609:AIISAS > 2.0. $\mathrm{CO} ; 2$.

Richardson, P., and T. McKee (1984), Average seasonal variation of the Atlantic Equatorial Currents from historical ship drifts, J. Phys. Oceanogr., 14(7), 1226-1238, doi:10.1175/1520-0485(1984)014<1226:ASVOTA $>2.0 . \mathrm{CO} ; 2$.
Richardson, P., and G. Reverdin (1987), Seasonal cycle of velocity in the Atlantic North Equatorial Countercurrent as measured by surface drifters, current meters, and ship drifts, J. Geophys. Res., 92, 3691-3708.

Richardson, P., and D. Walsh (1986), Mapping climatological seasonal variations of surface currents in the tropical Atlantic using ship drifts, J. Geophys. Res., 91(C9), 10,537-10,550, doi:10.1029/ JC091iC09p10537.

Richardson, P., S. Arnault, S. Garzoli, and J. Bruce (1992), Annual cycle of the Atlantic north equatorial contercurrent, Deep Sea Res. Part I, 39(6), 997-1014, doi:10.1016/0198-0149(92)90036-S.

Schouten, M., R. Matano, and T. Strub (2005), A description of the seasonal cycle of the equatorial Atlantic from altimeter data, Deep Sea Res., 52(3), 477-493, doi:10.1016/j.dsr.2004.10.007.

Servain, J., A. Busalacchi, M. McPhaden, A. Moura, G. Reverdin, M. Vianna, and S. Zebiak (1998), A Pilot Research Moored Array in the Tropical Atlantic (PIRATA), Bull. Am. Meteorol. Soc., 79(10), 20192031, doi:10.1175/1520-0477(1998)079<2019:APRMAI>2.0.CO;2.

Thierry, V., A. Treguier, and H. Mercier (2004), Numerical study of the annual and semi-annual fluctuations in the deep equatorial Atlantic Ocean, Ocean Modell., 6(1), 1-30, doi:10.1016/S1463-5003(02)00054-9.

Tziperman, E., L. Stone, M. Cane, and H. Jarosh (1994), El nino chaos: Overlapping of resonances between the seasonal cycle and the pacific ocean-atmosphere oscillator, Science, 264(5155), 72-74, doi:10.1126/ science. 264.5155 .72 .

von Schuckmann, K., P. Brandt, and C. Eden (2008), Generation of tropical instability waves in the Atlantic Ocean, J. Geophys. Res., 113, C08034, doi:10.1029/2007JC004712.

Wang, W., and M. McPhaden (1999), The surface-layer heat balance in the equatorial pacific ocean. Part i: Mean seasonal cycle, J. Phys. Oceanogr. 29(8), 1812-1831, doi:10.1175/1520-0485(1999)029<1812: TSLHBI $>2.0 . \mathrm{CO} ; 2$.

Weisberg, R., and T. Tang (1983), Equatorial ocean response to growing and moving wind systems with application to the Atlantic, J. Mar. Res. 41, 461-486.

Weisberg, R., and T. Tang (1985), On the response of the equatorial thermocline in the Atlantic Ocean to the seasonally varying trade winds, J. Geophys. Res., 90(C10), 7117-7128, doi:10.1029/JC090iC04p07117.

Weisberg, R., and T. Tang (1987), Further studies on the response of the equatorial thermocline in the Atlantic Ocean to the seasonally varying trade winds, J. Geophys. Res., 92(C4), 3709-3727, doi:10.1029/ JC092iC04p03709.

Weisberg, R., and T. Tang (1990), A linear analysis of equatorial Atlantic Ocean thermocline variability, J. Phys. Oceanogr., 20(12), 1813-1825, doi:10.1175/1520-0485(1990)020<1813:ALAOEA > 2.0.CO;2.

Xie, S.-P. (1994), On the genesis of the equatorial annual cycle, J. Clim., 7(12), 2008-2013, doi:10.1175/1520-0442(1994)007<2008:OTGO$\mathrm{TE}>2.0 . \mathrm{CO} ; 2$

Xie, S.-P., and J. A. Carton (2004), Tropical Atlantic variability: Patterns, mechanisms, and impacts, in Earth's Climate: The Ocean-Atmosphere Interaction, Geophys. Monogr. Ser, vol.147, edited by C. Wang, S.-P. Xie, and J. A. Carton, pp. 121-142, AGU, Washington, D. C.

Yu, X., and M. McPhaden (1999), Seasonal variability in the equatorial Pacific, J. Phys. Oceanogr., 29(5), 925-947, doi:10.1175/15200485(1999)029<0925:SVITEP $>2.0$. CO;2

H. Ding, N. S. Keenlyside, and M. Latif, Leibniz Institute of Marine Sciences, Kiel University, East Shore Campus, Wischhofstrasse 1-3, D-24148 Kiel, Germany. (hding@ifm-geomar.de) 